\title{
Examining the What, Why, and How of Multilingual Student Identity Development in Computer Science
}

\author{
SHARIN RAWHIYA JACOB, JONATHAN MONTOYA, HA NGUYEN, \\ DEBRA RICHARDSON, and MARK WARSCHAUER, University of California, Irvine
}

\begin{abstract}
Developing student interest is critical to supporting student learning in computer science. Research indicates that student interest is a key predictor of persistence and achievement. While there is a growing body of work on developing computing identities for diverse students, little research focuses on early exposure to develop multilingual students' interest in computing. These students represent one of the fastest growing populations in the US, yet they are dramatically underrepresented in computer science education. This study examines identity development of upper elementary multilingual students as they engage in a year-long computational thinking curriculum, and follows their engagement across multiple settings (i.e., school, club, home, community). Findings from pre- and post-surveys of identity showed significant differences favoring students' experiences with computer science, their perceptions of computer science, their perceptions of themselves as computer scientists, and their family support for computer science. Findings from follow-up interviews and prior research suggest that tailored instruction provides opportunities for connections to outof-school learning environments with friends and family that may shift students' perceptions of their abilities to pursue computer science and persist when encountering challenges.
\end{abstract}

CCS Concepts: • Social and professional topics $\rightarrow$ Computer science education; K-12 education;

Additional Key Words and Phrases: Computer science, computational thinking, identity, multilingual, English learner

\section{ACM Reference format:}

Sharin Rawhiya Jacob, Jonathan Montoya, Ha Nguyen, Debra Richardson, and Mark Warschauer. 2022. Examining the What, Why, and How of Multilingual Student Identity Development in Computer Science. ACM Trans. Comput. Educ. 22, 3, Article 29 (September 2022), 33 pages.

https://doi.org/10.1145/3500918

\section{INTRODUCTION}

It is well established that there is a strong relationship between students' perceptions of themselves as professionals in Science, Technology, Engineering, and Mathematics (STEM) and their career interest $[7,9,58,93]$, indicating the importance of developing young peoples' attitudes and interests early on. Furthermore, student interest is a key predictor of persistence and achievement

We would like to thank the National Science Foundation (Grants no. 1738825 and no. 1923136) for providing the funding that made this project possible. Findings expressed in this work are those of the authors and do not necessarily reflect the views of the National Science Foundation.

Authors' address: S. R. Jacob, J. Montoya, H. Nguyen, D. Richardson, and M. Warschauer, University of California, Irvine, Irvine, California 92697; emails: \{sharinj, jlmonto1, thicn, djr, markw\}@uci.edu.

\section{(i) (3)}

This work is licensed under a Creative Commons Attribution-NonCommercial International 4.0 License.

(C) 2022 Copyright held by the owner/author(s).

1946-6226/2022/09-ART29 \$15.00

https://doi.org/10.1145/3500918 
[59]. Thus, it is critical that we develop strategies for broadening the participation of students from diverse backgrounds who identify with the discipline of computer science (CS).

CS knowledge, skills, and attitudes are becoming increasingly necessary for full participation in today's society [128]. The US Bureau of Labor Statistics predicts there will be 1.4 million CS job openings by 2026 with only 500,000 qualified graduates to fill these positions [94]. In response to this overwhelming need, the White House's Computer Science for All (CSforAll) initiative has emerged over the last few years to help all students become developers, not just consumers of technology [117]. In order to broaden participation in computing, a critical task is leveraging the wealth of talent in this nation's diverse population. This is especially important for the large and growing population of students designated as English learners. This population grew from 8.1 $\%$ (or 3.8 million students) in 2000 to $9.6 \%$ (or 4.9 million students) in 2016 and it is projected to reach $25 \%$ of the student population in 2025 [81], but it is seriously underrepresented in education and achievement [80]. Leveraging these students' linguistic and cultural diversity enables new perspectives that foster creative and innovative approaches to problem solving. Such new perspectives are not only needed to drive future technological advances; they are also becoming increasingly critical in solving pressing problems across essential domains of the human experience [85, 127].

Unfortunately, a number of factors explain the chronic lack of representation of linguistically diverse students. First, there is a dearth of data about students designated as English learners (ELs) in CS courses. As schools base their decisions on data [110], this means that educators and stakeholders must rely on assumptions about the success of students designated as ELs in CS, or that they ignore these subgroups entirely. To exacerbate this issue, schools with $12 \%$ or greater students designated as ELs offer half as many CS courses as other schools [80]. In addition to lack of access, pervasive stereotyping in the field is perpetuated through media representation. Only about $16 \%$ of students report seeing computer scientists who look like them in the media, which sends messages to diverse learners about who does CS [27]. Finally, much of the CS curricula implemented to date do not reflect the traditions and values of culturally and linguistically diverse students and their families [79]. Purposefully tailored instruction can address these issues by providing opportunities for connections to out-of-school learning environments, in which students are with friends, family, and community, which may shift students' perceptions of their abilities to pursue CS and empower them to persist when encountering challenges.

Issues regarding the classification of ELs only exacerbate inequities for these students. These students are commonly referred to as ELs because in many states the English language proficiency (ELP) exam represents the only criterion for school and districtwide designations of students' language proficiency. Other oftenly used criteria to designate students as ELs include standardized test scores in Mathematics or English Language Arts, teacher assessment of progress, and parental approval [18]. Unfortunately, these are the only factors that many CS and STEM educators consider when studying approaches to engaging these students in the classroom. Examining students in terms of their language proficiency fails to account for the linguistic and cultural assets that these students bring to the classroom $[75,126]$.

There are several reasons why the terms English Learner and English Language Learner are problematic [75]. First, they inherently devalue the cultural and linguistic resources that students bring to the classroom. Second, they do not reflect cultural diversity of students with these labels, as the focus is on learning English and not on the languages that these students already speak. Third, the apparent neutrality of the term renders them free from scrutiny. Fourth, they confuse students who speak English at home with those who are learning English for academic purposes, therefore delegitimizing the existing linguistic resources students can leverage for making sense of complex phenomena. Finally, they do not make room for bilingualism in instruction. 
Flores and Rosa [44] argue that designations of ELs, heritage learners, and Standard ELs are constrained by raciolinguistic ideologies that lead to deficit based views of these students. They call for the denaturalization of traditional linguistic categories by reimagining education policy in order to focus on the wealth of resources imbued by these students. Building on their work, we argue that multilingualism and plurilingualism facilitate learning [46], and that multilingual students have an advantage over their monolingual counterparts in that learning involves the growth of both linguistic and subject matter competencies [102]. Multilingual students' identities are assets that can be leveraged to facilitate learning, and contribute to these students' active participation in the field of CS [62]. Therefore, we will use the term multilingual throughout this study to refer to students who use more than one language in their daily lives and may be learning English in school.

It is important to underscore the diversity of multilingual students, especially regarding their cultural backgrounds, languages spoken, immigration status, and time residing in the US. Some students may be refugees whose previous instruction in their home languages and/or English may have been disrupted. Most of the students in this study are residents of the southwestern state of [name of state blinded for review] and children of immigrants who arrived in the US as young children. These children speak Spanish at home and are formally schooled in the US in English [83] Given their diversity, it is important to avoid overgeneralizations about multilingual students as a whole; nevertheless, these students bring a shared positionality within educational institutions with regard to cultural and linguistic diversity.

In this study, we investigate whether early exposure to a computational thinking curriculum that has been adapted to meet the needs of culturally and linguistically diverse students appears to support identification with CS. We implement a pre- and post-survey design intended to measure multilingual students' identification with CS. The survey is followed up by interviews that probe further into the why and how of this identification. These findings can potentially advance our understanding of how multilingual students develop discipline-specific CS identities through their engagement in a well-tailored curriculum.

Our study asks the following research questions:

(1) To what extent do multilingual students' CS identities change after participating in a yearlong computational thinking curriculum designed to meet their linguistic and sociocultural needs?

(2) What factors contribute to these changes? How are multilingual students' identities shaped by participation in both formal and informal learning environments?

\section{BACKGROUND}

\subsection{Identity Studies in CS Education}

There is a nascent but growing body of work examining equitable CS education for multilingual and racially diverse students that seeks to advance our knowledge of how curriculum and practice can be designed to leverage the varied resources of these students and their communities. In a review of previous works, student identification with CS was examined through the construction of learning environments to support identity growth [113]. A recent study investigated how students from marginalized backgrounds reshaped dominant narratives, in particular by integrating quilting with paper circuitry [101]. Students who quilted with paper circuits were able to leverage their rich cultural traditions to reframe their participation in computing, utilizing their computing identities in novel ways. Similarly, there have been several efforts to draw upon existing cultural practices and traditions in students' families to reveal the mathematical and computational concepts they already use. Existing traditions in indigenous communities, such as sewing, weaving, 
and decorative beading, have been connected to engineering and computing practices through the utilization of electronic textiles (e-textiles) [67]. E-textiles blend crafting practices with microprocessors, light bulbs, and sensors to explore science and engineering principles, such as electricity and circuits, in culturally responsive ways.

An e-textiles science unit was piloted in a classroom containing $30 \%$ students designated as ELs [60]. Researchers observed a marked increase in these students' participation compared to classes that taught electricity and circuits through traditional means. Reasons for this increased participation included the following: (1) students and families valued the work completed by hand and that drew upon students' conceptual resources; (2) students took their work home and received homework assistance from family members who drew on their crafting expertise; (3) students developed a collaborative environment in which they were able to share with their peers their expertise on how to overcome various obstacles; and (4) students were able to choose and personalize their projects which led to greater identification with their creations.

Another mechanism for increasing interest in computing involved integrating computational concepts with K-12 subject areas. Computing has been integrated into a Science Technology Engineering Arts and Mathematics (STEAM) curriculum to encourage Black girls to develop wearable technologies that they could display during their dance choreographies [5]. Through this curriculum, girls were able to leverage their interests to develop CS identities while physically embodying computing concepts through creative expression. Another study, a year-long upper elementary CS-integrated computational thinking and literacy curriculum, aligned with the grade 3-5 English Language Development Standards and Common Core State Standards for English Language Arts, was developed to increase both CS learning and literacy development among predominantly Latinx, multilingual students [64]. This curriculum helped to facilitate these students' expression and creativity, and when combined with structured instructional practices, it appeared to support their development of computational thinking skills and overall identification with the field of CS [62,63].

Other work has focused on bridging the gap between formal and informal CS learning environments by leveraging multilingual students' existing resources to enhance their engagement with CS. The use of translanguaging by middle school teachers has been studied to determine how it facilitates CS learning [126]. Drawing on the theory of translanguaging [47], Vogel et al. [126] situate coding as a discourse that is embedded within historical, cultural, and social contexts, arguing that educators and policy makers need to bring underserved groups such as emergent bilinguals into this discourse. Translanguaging represents a mechanism for leveraging multilingual learners' full linguistic repertoires as they engage in computational literacies. In addition to leveraging linguistic resources, researchers have implemented strategies for engaging families in the STEM education of children from predominantly Latinx backgrounds through community-based engagement efforts [35], such as hosting after-school Spanish family coding nights [33]. Students' individual and collective interests have also been leveraged in support of CS learning, such as building on Black boys' interests in video games to engage them in looking "under the hood" at the underlying technology, which led to their increased perceptions of peers as resources as well as greater access to technical literacies [65].

Challenges with material notwithstanding, diverse students from marginalized groups may lose interest in science classes very early in their academic careers, especially when the subject is presented as unrelated to their own lives and contexts [38]. Successful intervention for these students consists of making science relevant by drawing from students' own contexts and funds of knowledge [12]. This approach acknowledges the value that students of all backgrounds bring to the materials with which they engage, and validates these identities beyond mere teaching of the scientific model of thought. Additionally, students from predominantly Latinx cultures often 
favor relational learning over independent, noncollaborative approaches [107]. It is unsurprising that students from underrepresented groups often become more disengaged from school in upper elementary and middle grades-the disinterest of a previously engaged student develops alongside their experiences of science as noncollaborative or competitive, the product of a culture to which they do not belong [11]. Culturally responsive teaching approaches value interdependence and collaboration, and better prepares all students for the actual demands of creative thought and collaborative work in later CS careers [1]. In practice, this type of instruction provides opportunities for peer interaction and collaborative learning [20], contextualizes lessons and projects in the experiences and skills of students' homes and communities [82], and relies on an awareness of how culture and identity inform student interests in pursuing science [24]. For Latinx students in particular, educators can nurture their interest in CS by increasing their exposure to role models, personally meaningful coursework, and instruction that meets their cultural and linguistic needs [28]. Finally, for Latinx students who are also learning English as a second language during K-5 grades, instruction must meet learners' needs for scaffolded language learning, so that they acquire the language of science along with its methods; truly responsive teaching must be both culturally and linguistically sensitive [63].

These findings establish the following factors that contribute to students' increased identification with computing: (1) reshaping dominant narratives of who does CS, (2) making crosscurricular connections, (3) providing culturally responsive teaching, and (4) leveraging their existing resources to engage in CS content. Despite the many common themes characterizing multilingual students' development of CS identities, overgeneralizations regarding this student population should be avoided, as these students display substantial variation with regard to factors including but not limited to language, culture, immigration status, and previous schooling. What follows is our theoretical framing of disciplinary identification, as experienced in particular by multilingual students.

\section{THEORETICAL FRAMEWORK}

\subsection{Constructing Disciplinary Identities}

Identity has recently gained traction as an essential educational construct that provides a framework for understanding student learning in STEM. Identity studies have traditionally focused on the types of knowledge and expertise necessary to gain entrance into communities of practice $[17,22]$, but there is a growing body of work that situates identity as negotiated and contingent upon broader social, cultural, and historical contexts [21]. In this study, we draw from social practice theory to characterize identity as a dense network of relationships and interactions organized around structured activities [106]. These relationships are embedded in powerful narratives about what it means to be a competent actor within sociocultural and historical contexts (e.g., a computer scientist, a good student, and a person from a specific racial, cultural, or linguistic background) [21]. Therefore, as students position themselves within educational settings, their actions are constrained by the socially constructed norms, rules, and expectations that govern these spaces. A students' positionality is not static: it is dependent upon how it is taken up over time by the actors residing in these spaces, and it can be directed toward or against the norms governing these spaces.

The notion of identity can be used to better understand student learning as it is constructed through engagement or disengagement in disciplinary practices [65, 125]. Our framing of this issue borrows heavily from DiSalvo et al. [65]. Social norms and practices represent one mechanism for governing student disciplinary identification. Students are more likely to identify with a discipline if they consider its practices to be typical of their social sphere $[65,119]$. Conversely, students will disidentify with a discipline if they perceive its practices to be socially atypical. Research 
indicates that disciplinary disidentification leads to decreased academic achievement, downward economic mobility, and social inequality $[41,118,119]$. It can also spread through peer groups by way of peer pressure [118]. Due to its virulence, disidentification represents a key contributor to underrepresentation of marginalized students, such as women, Black students, and students of color [70]. It thus becomes key to distinguish incidences when students "choose not to learn" from those in which they have difficulty grappling with the material, when examining the effects of disidentification on student learning [71].

As identity is constructed through practice, it involves acquiring the knowledge, skills, and attitudes necessary to be perceived as a competent actor within a given discipline. Identity and learning are inextricably linked to learner participation in disciplinary practices across contextualized settings [12, 23, 90, 106]. Our theoretical framework relating these two concepts, learning and identity, borrows heavily from Van Horne and Bell [125]. Learning occurs in space and time across multiple contexts (in school, out of school, and at home) $[8,13,98,99]$ and when it is socially relevant $[25,53]$. Providing these conditions helps to democratize knowledge and access to socially valued practices [133], thereby fostering identity development through meaningful interaction $[30,89]$. As students experience CS across time and multiple spaces, they begin to construe what it means to be part of an imagined community and how they themselves fit within these communities [34, 91].

During identity construction, there is a dynamic interplay between student perceptions of who they are and who they desire to be, which is often guided by their perceptions of what competent actors are like with a given field [21]. These perceptions are influenced by how students' actions are taken up and received by socially recognized members of the community. Therefore, identity development encompasses how students view themselves in relation to others, through their identification with disciplinary practices, as they participate in communities of practice [10]. Curricula often provide an implicit guide for how learners might engage with a given discipline. Thus, curricula that connect formal learning environments to out-of-school contexts strengthen the development of disciplinary identities [86].

\subsection{Multilingual Student Identity Construction}

Crump [32] views language and identity as inextricably linked. Both are dynamic and fluid entities, and both represent devices by which participants become members of academic communities [34]. Currently, educational policy makers distinguish between native and non-native speakers of English, and the designation of EL only compounds the extent to which students are labeled according to what they still have to learn, as opposed to what they already know. By using the label multilingual instead, we acknowledge the multiple competencies that these students bring to bear [29], and the duality of cultures and worlds that they inhabit. First and second (or third languages) are used sequentially, to indicate that the first language can be used in service of developing the second language and content knowledge, and vice versa [2].

Furthermore, not only are multilingual students linguistically diverse, but they also reside in sociocultural contexts that include cultural, familial, and social resources that can be leveraged to foster learning and encourage the development of disciplinary identities. Elementary ELs come from diverse communities that each have their own goals, values, and particular ways of evaluating and interacting with the world. Before entering school, children are socialized into the language of their homes and communities [54]. Over time, they encounter new cultural contexts and practices that are distinct from their communities of origin. Students leverage their everyday sense-making abilities learned from their homes and communities to interpret scientific phenomena they encounter in the classroom $[73,77,78]$. Through this sense making of scientific practices, 
such as identifying problems and designing solutions, students develop a deeper understanding of scientific principles.

Instructional practices that promote inquiry-based, content-first approaches apply inductive methods of learning that build on students' existing resources by allowing them to use their everyday sense-making abilities to access content [19]. As students negotiate meaning in STEM classrooms, they make connections between teacher output and scientific artifacts, while problematizing knowledge and questioning misconceptions [48]. Bridging the gap between home and school learning increases their identification with academic curricula and discipline-specific content [87]. Instruction that draws on students' existing resources presents a particularly useful approach for engaging multilingual students in STEM education [18].

\section{RESEARCH CONTEXT}

\subsection{Multilingual Students and CS Education}

Several social, cultural, and linguistic factors contribute to the marginalization of multilingual students in CS education. First, these students come from socioculturally and linguistically heterogeneous backgrounds that are poorly understood. For instance, students are better able to leverage their first language in service of learning when they come from linguistically homogeneous communities [18]. Students from linguistically heterogeneous communities, however, may focus on salient aspects of variation among linguistic registers in both written and oral communication to facilitate STEM learning [18]. The students participating in our study come from communities and families that predominantly speak Spanish, but they are formally schooled in English in US schools. Therefore, these students tend to pay special attention to oral and written genres of informal English and to use their everyday sense-making abilities to interpret abstract concepts.

\subsection{The Research Practice Partnership}

The purpose of this study is to examine the identity development of upper elementary multilingual students through their participation in a year-long computational thinking curriculum designed to meet their cultural and linguistic needs. We follow student participation across multiple settings (including school, club, home, and community). The context for this study is a research practice partnership (RPP), the goals of which are to address core problems of practice facing a diverse school district implementing CSforAll initiatives and to determine how to meet the needs of the district's multilingual students. Western University (pseudonym) is partnering with a County Department of Education and a large urban school district to form a collaborative network of university and K-12 researchers and practitioners with the aim of promoting computational thinking for students in grades 3-5. This network functions through principles of Design-Based Implementation Research (DBIR), designing instructional materials to implement, study, and refine alongside the county and district.

The participating southwestern [name of state and district blinded for review] district is among US districts with the highest percentage of Latinx students (93\%), low-income learners (89.7\% receiving free or reduced-price lunch), and students designated as English language learners (62.7\% in the elementary grades). In [name of city blinded for review], $71 \%$ of foreign-born individuals are from Mexico; $8 \%$ are from Asia; and $88 \%$ of Hispanics are from Mexico. Consistent with the broader [name of city blinded for review] community, the strong majority of the students in the participating district are of Mexican heritage, but smaller numbers of students are primarily from El Salvador, Guatemala, and Honduras. This district is seeking to improve student academic achievement and interest in STEM through programs that support instructor innovation and emphasize integration of STEM and English language arts curricula. 
4.2.1 Positionality Statements. As first author, my family history positions my research interests in how education can provide tools that help students from marginalized backgrounds overcome adversity and succeed in STEM. Growing up as an Egyptian American in a high-poverty household with disabled parents has fostered deep empathy for historically marginalized students. My personal connection with students who struggle to celebrate differences in language, ethnicity, ability, and income fuels my work as a former language teacher and educational researcher. The second author's research explores STEM and Career and Technical Education (CTE) pathways. As a first generation college and high school graduate, he is intimately familiar with the communities he serves. As a mixed Chicano and Portuguese scholar, he leverages his linguistic resources as well as his decades-long experience as a practitioner in secondary and post-secondary STEM and CTE classrooms. The final author is a former Spanish bilingual math and language teacher and first generation college student with a lengthy history of teaching and research focused on educational equity for diverse learners. These first-hand experiences have informed our data analysis and contextualized our understanding of identity development in culturally and linguistically diverse children.

\subsection{Overview of the Computational Thinking Curriculum}

Researchers worked collaboratively with teachers to adapt an existing grade 3-5 curriculum created by a path-breaking initiative that seeks to normalize CS education in a large urban school district from PreK through 12th grade. The curriculum was deemed well-suited to our research purposes as it aligns with the Computer Science Teaching Association K-12 Computer Science Standards and emphasizes the teaching and learning of computational thinking. The curriculum was adapted to meet the needs of the district's culturally and linguistically diverse students. Designbased implementation research was used to bridge theory and practice in the design of the instructional materials. The theoretical underpinnings of curriculum design were grounded in effective practices for engaging multilingual students in STEM, as outlined in a recent report of the National Academies of Sciences [18]. According to this report, the following findings have been shown to be effective in increasing academic and social outcomes for multilingual students in STEM: (1) engaging students in disciplinary practices, (2) encouraging rich classroom discourse, (3) building on students' multiple meaning-making resources, (4) encouraging students to use multiple registers and modalities, and (5) providing explicit focus on how language functions in the discipline. Given the paucity of empirical evidence supporting the engagement of multilingual students in CS education, we worked collaboratively with teachers and administrators during a week-long summer institute to develop a curriculum based on the findings of this report, while tailoring materials to meet the needs of the district's diverse learners. This was achieved by (1) aligning the curriculum with CS and literacy standards and integrating inquiry-based approaches, (2) providing multiple opportunities for collaboration, (3) providing culturally responsive pedagogy and materials, (4) presenting multimodal options for learning, and (5) providing intensive linguistic scaffolding. What follows is an explanation of how our curricular adaptations align with effective practices for teaching STEM to multilingual students.

First, the curriculum integrates CS and English Language Arts tasks to engage students in disciplinary practices through inquiry-based exploration, modification, and creation of products. Research indicates that STEM instruction is best provided when instructional practices leverage multilingual students' cultural and linguistic backgrounds [15, 40]. To integrate CS inquiry-based approaches into the curriculum, we utilized the " $5 \mathrm{E}$ " model of inquiry to guide unit development: Engage, Explore, Explain, Elaborate, and Evaluate. Throughout each phase, the teacher facilitated meaningful peer-to-peer discourse about students' problem-solving processes. In this way, 
inquiry-based learning provides authentic contexts for language that leverage multilingual students' existing resources while making instruction more engaging for them [31, 66, 108].

Second, the curriculum encourages rich classroom discourse through explicit suggestions of activity formats (e.g., individual thinking time, pair programming, small group, whole class) that engage students in using disciplinary language in multiple contexts. This provides opportunities for collaboration that have been shown to facilitate learning for predominantly Latinx communities [107]. Furthermore, the professional development associated with the curriculum focused on teachers noticing students' discourse to facilitate productive talk [114].

Third, strategies that teachers use to build on students' existing resources to acquire disciplinary language and CS were highlighted through unplugged activities. These activities built on students' everyday knowledge and semiotic resources while leveraging their own ways of explaining CS concepts. During monthly professional development sessions, we included teacher tips for teacher "talk moves" [84], such as asking for clarification and leveraging students' own ways of explaining to guide them toward more formal language and advanced CS concepts. Furthermore, culturally responsive childrens' story books depicting diverse characters who were pioneers in CS and engineering fields were selected to make the content relatable to students. While racial and cultural stereotypes can have negative effects on the STEM career aspirations of underrepresented youth [92], research has also demonstrated that same-race characters can have beneficial effects on Latinx students' positive dispositions and attitudes toward CS [124].

Fourth, visualizations and physical, unplugged activities were built into the curriculum to engage students in multiple modalities, including linguistic modalities of talk and text, as well as nonlinguistic modalities such as gestures, pictures, and symbols, to better teach key vocabulary and computational thinking concepts [72]. For example, students learned about the concept and term "parallelism" first through an activity encompassing body movement and then through visualizations. This approach lies at the heart of translanguaging, as students are able to leverage their full meaning-making repertoires to engage in CS learning [126].

Fifth, the curriculum provides explicit focus on how language functions in the discipline by integrating language frames, which teachers made available for use by students during project reflections, peer feedback, pair programming, and help-seeking. The development of linguistic frames is grounded in systemic-functional linguistic theory [56], which proposes that language is an inherently social phenomenon in which communication serves to operationalize the syntactic and formal structures embedded in the language of a given discipline. Culturally sustaining pedagogies have been merged with systemic functional linguistics [112] to develop students' metalinguistic awareness of contextualized language use while giving students the agency to provide meaningful critique of how knowledge is constructed. To implement linguistic scaffolding, sentence frames were printed on student-friendly placemats for each of the lessons; these were used during reflection activities to reinforce concepts and provide guided language instruction. We were careful not to provide the frames during open conversation so that students had the agency to make their own rhetorical choices, while engaging in authentic language use arising from peer-to-peer interaction. This strategy is corroborated by recent research on the affordances and challenges involved in using sentence frames and when best to employ them so that they do not stifle communication [52].

Finally, the curriculum integrates computational thinking and literacy instruction by aligning the materials with English Language Arts classes. This alignment was achieved by leveraging the affordances of media-rich programming environments such as Scratch to teach coding and decoding block-based commands and projects in the narrative and informative textual genres. Furthermore, English Language Arts lessons were developed around our culturally responsive stories to teach narrative genres, while fostering dispositions such as perseverance and iteration that are 
integral to the design process. Finally, CS disciplinary activities and learning goals were also aligned with standards so as to guide teachers and set clear expectations for students: researchers and teachers aligned materials with the Common Core State Standards for English Language Arts (ELA), and the statewide Department of Education English Language Development (ELD) Standards.

These strategies and principles were employed to promote students' inclusion in the CS community of practice. We aimed to develop students' CS knowledge and language through interaction and regular participation in profession-like practices and activities. Perhaps the most important contribution of our curriculum was its "content-first" approach to learning: students were encouraged to access the discipline before engaging in linguistic tasks, which might otherwise have unnecessarily averted resources away from learning CS [72]. It is through content learning that students interact and communicate with one another and begin to co-construct knowledge, thus becoming active creators of disciplinary practices. The goal is for students to learn as scientists would, by developing an understanding of complex phenomena and then creating the most efficient terms for describing what they observe. The practices presented in this curriculum promote understanding and learning as the essential goals of real-life disciplinary practice.

This content-first approach relied on two principles of practice. First, the curriculum was taught inductively through an inquiry-based approach. For example, if students are supposed to learn the concept of loops, first they might do a dance involving repeating moves, mapping out the sequence of repeating moves and actually embodying the concept, before the term "loop" is presented. Then, after leveraging their multiple resources to understand the concept before the term, the teacher would show what loops look like in Scratch. With this knowledge, students would then practice programming projects that require loops, like the "Build a Band" project in which students use loops to create a musical concert. Second, the block-based, media-rich programming environment Scratch [104] holds real promise for authentic disciplinary CS learning. Unlike more abstract programming environments, the language used during interactive programming in Scratch is often colloquial, such as "drag this block here." Herein lies the real power of tools such as Scratch: they empower students to access the discipline and develop computational thinking without having to complete challenging linguistic tasks that may distract them from the primary goal of developing an understanding of CS content. It was not until students had completed the projects and shared them with their peers for feedback that the teachers presented the linguistic scaffolding to explicitly teach CS language functions and scaffold their disciplinary language.

\subsection{Teacher Professional Development}

To support the piloting teachers, the project included professional development (PD) throughout the year during team meetings and classroom debriefs, as well as during the summer institute. The PD structure was designed to engage teachers in the types of inquiry-based models fundamental to CS instruction; it followed practices of effective learning and teaching in STEM and CS education to multilingual students [18], and was then tailored based on suggestions made by researchers and practitioners $[50,76]$. Furthermore, the PD was intended to strengthen communities of practitioners: teachers with more experience in teaching the subject area would share resources and insights with colleagues to meet the constraints of local contexts [76].

The summer institute PD began by establishing a shared understanding within the community of practitioners. Elementary school teachers who had taught the CS curriculum defined computational thinking and articulated how to scaffold instructional practices for diverse learners. They noted similar linguistic needs of students new to the CS curriculum, including vocabulary development and increased exposure to the language of the discipline. Researchers and teachers then collaborated to develop linguistic frames to scaffold both the academic language related to CS 
concepts and the functions of social interaction. The design of language support was operationalized through the following process: (1) a researcher (first author) modeled a 15-minute CS mini-lesson on algorithms in which teachers and administrators played the roles of students; (2) a language recorder (third author) took note of the types of language use that occurred during the lesson; (3) teachers were explicitly asked to focus on language usage; (4) researchers guided the teachers in discussing actual language use versus desired language use; and (5) the group worked together to develop language scaffolds for the mini-lesson. During the post mini-lesson discussion, the teachers noticed that they used their everyday language to discuss the concept of algorithms. While students initially use their everyday sense-making abilities to access CS concepts, explicit teaching of the corresponding language forms and functions was integrated to reinforce student understanding and develop their linguistic repertoires. Although we provide explicit teaching of language functions, we go beyond the mere use of linguistic scaffolding to conceptualize a translanguaging stance that builds on students' everyday language practices and existing sense-making repertoires [126]. To this end, we use inductive approaches to learning that engage students in sense-making through multiple modalities, which has been shown to promote multilingual student understanding of computing concepts [55]. These practices when used in concert with one another are empirically supported and effective for engaging multilingual students in STEM [18].

After this PD activity, we worked with teachers to develop language scaffolds for each lesson of the five-unit curriculum and aligned the sentence frames with the ELA and ELD standards. These scaffolds were initially designed for use in peer feedback, articulating driver and navigator roles during pair programming, and asking for assistance during the debugging process. Our PD also emphasized issues of equity and access, following suggestions of other CS teacher training programs [50]. During a gallery walk, teachers read and reflected on statistics of K-12 CS education, such as "93\% of parents want CS education for their children, but only $40 \%$ of schools offer programming" [43]. Teachers commented on problems of practice specific to their contexts that challenged these statistics. For example, they pointed out that parents in their classes might be hesitant rather than enthusiastic about CS education because they equated computing with gaming. A discussion of how to increase parental buy-in occurred organically. For example, teachers suggested providing an opportunity for students to showcase their computational artifacts to their families and the greater community. These artifacts would link computational thinking concepts to students' experiences at home (e.g., storytelling and community-based projects) and in school (e.g., games that provide upper elementary students opportunities to teach their K-2 classmates how to calculate fractions).

\section{METHOD}

\subsection{The Current Study}

Western University partnered with a county Department of Education and a large urban school district to form a collaborative network of university and K-12 researchers and practitioners with the aim of promoting computational thinking for students in grades 3-5. This network functioned through principles of DBIR, designing interventions to implement, study, and refine alongside the county and district. The study was situated in a district among those with the highest percentages of low-income students (91\%), Latinx students (96\%), and students designated as ELs (63\% in elementary grades) in the nation.

5.1.1 Context. This study took place in seven upper elementary (grades 3-5) classrooms across a large urban school district. Student demographics at the classroom level broadly mirrored those at the district level. 
5.1.2 Participants. A total of seven teachers and their classrooms were selected in the partnership program based on their prior experience and interest in teaching CS to upper elementary students. Three of the teachers were Asian, two were Latinx, and two were White. Four taught mainstream general education classrooms; one taught a full-inclusion special education classroom serving both general and special education students with mild/moderate levels of disability; one taught a Gifted and Talented Education (GATE) class in which most of the students had been identified as gifted, typically through channels including teacher recommendations, writing scores, grades, and achievement test scores. In all of the aforementioned classrooms, instruction was primarily in English, but students were consistently encouraged to leverage their linguistic and semiotic resources during CS learning. The seventh teacher taught a dual-immersion classroom composed of students who predominantly spoke Spanish at home, and many of whom were designated as having mild to moderate disabilities. She was a Mild/Moderate Special Education teacher who provided multiple opportunities for instructional and socioemotional support to meet the needs of her students. She was Latina and bilingual in English and Spanish, and she provided bilingual instruction to her students during the piloting of the curriculum. Participating teachers had extensive experience teaching multilingual students and were provided regular districtwide training on serving this population. All the students in these seven teachers' classes (total $N=108$ ) participated in the project and thus were part of the study.

5.1.3 Implementation. The participating teachers piloted the year-long, five-unit computational thinking curriculum in their classrooms once a week for a lesson duration of 50 minutes.

\subsection{Data Sources}

5.2.1 Research Design. We utilize a mixed-methods sequential explanatory design in which the quantitative phase of data collection is followed by the qualitative phase [61]. The rationale of the sequential explanatory design is that it provides a better understanding of the research problem, as the qualitative data can be used to clarify and explain the quantitative analysis [61]. In our study, the pre- and post-test was administered at the beginning of the year to better understand how students develop their CS identities through their participation in the year-long curriculum. We followed the post-test with semi-structured interviews to probe more deeply into student responses and provide plausible explanations for trends observed in the survey responses.

5.2.2 Quantitative Data. Items from the validated survey Is Science Me? (ISM) [49] were adapted to capture students' attitudes toward CS disciplines and careers and the influence of families and peers on student identification with computing (the adapted survey was renamed Is Computer Science Me? [ICSM]). The constructs were grounded in research on the roles of family support [49], school experiences [96], and self-perceptions [39]. The survey was presented in English using informal language appropriate for students with strong informal spoken and written language proficiency. Most survey item responses consisted of three-point Likert scale items, with validating factor analysis to establish moderate to high levels of internal consistency via Cronbach's alphas and McDonald's omegas [45]. Categorical aggregates were calculated by summing responses across items relating to (1) Experiences with Computers, (2) Perceptions of Computer Science, (3) Self-Perception as Computer Scientist, (4) Family Support for Computer Science, and (5) Friend Support for Computer Science.

5.2.3 Qualitative Data. To develop the interview questions, we constructed open-ended questions based on the constructs underlying the ICSM survey to gain a more in-depth understanding of student responses. We paid special attention to how interview findings might relate to the quantitative survey findings. For the interviews, we selected from each classroom four students 
Table 1. Student Demographics

\begin{tabular}{lr}
\hline Variable $(n=103)$ & Mean \\
\hline Have Computer Access & $84 \%$ \\
Mother Attended College & $52 \%$ \\
Father Attended College & $40 \%$ \\
Sibling Attended College & $28 \%$ \\
Mother has Computer Science Career & $10 \%$ \\
Father has Computer Science Career & $10 \%$ \\
Sibling has Computer Science Career & $11 \%$ \\
\hline
\end{tabular}

designated as ELs $(N=18)$, two with bridging programming experience and linguistic proficiency as indicated by the California English Language Development standards, and two with emerging programming experience and linguistic proficiency. We relied on teacher judgment to select students and encouraged teachers to use the California English Language Development standards in selecting students. Teachers had intimate knowledge of these standards as they were used to develop the linguistic scaffolding embedded in the instructional materials.

\subsection{Data Analysis}

Research question (1) was addressed by contrasting pre-test and post-test responses to the ICSM survey. The mean post-test minus pre-test difference in student response, its standard error, $t$ statistic, and effect size were calculated for each individual survey item, as well as for the categorical aggregates. Significance of the mean-difference was evaluated using a $t$-test, since the sample size is sufficient to justify asymptotic approximations. Unreported results using Wilcoxon signedrank tests yielded identical findings in terms of the significance of differences across items and aggregates.

Research question (2) was dedicated to data analysis using top-down and bottom-up qualitative coding [109], starting with categories from prior research on our theoretical framework for developing CS identities in multilingual students and refined based on emergent themes from the study. Two researchers collaborated during the first cycle of coding to assign preliminary codes to text that pertained to theory on student identification with CS. Upon coding five interviews, the two researchers then convened to discuss and consolidate the preliminary codes. After this discussion, the lead author applied the consolidated codes to the remaining interviews, generating new codes when text pertaining to the research questions did not match the existing codes. During the second cycle of coding, the researchers combined codes into categories and subcategories to reveal emerging themes of the study. After coding all of the interviews, two researchers (first and second author) selected $10 \%$ of the interviews and conducted an interrater reliability check. Upon initial coding of the interviews, the two researchers reached $91 \%$ agreement.

\section{RESULTS}

\subsection{Breakdown of Student Demographics}

To better understand students' previous experience with CS, we provide a breakdown of student demographics based on their access to computers, the education of their parents and siblings, and their parents' and siblings' exposure to CS careers (Table 1).

\subsection{ICSM? Survey Results}

Figure 1 presents students' average pre- and post-survey responses for the categorical aggregate items in the ICSM survey, along with their $95 \%$ Confidence Intervals. Inferential statistics indicate 


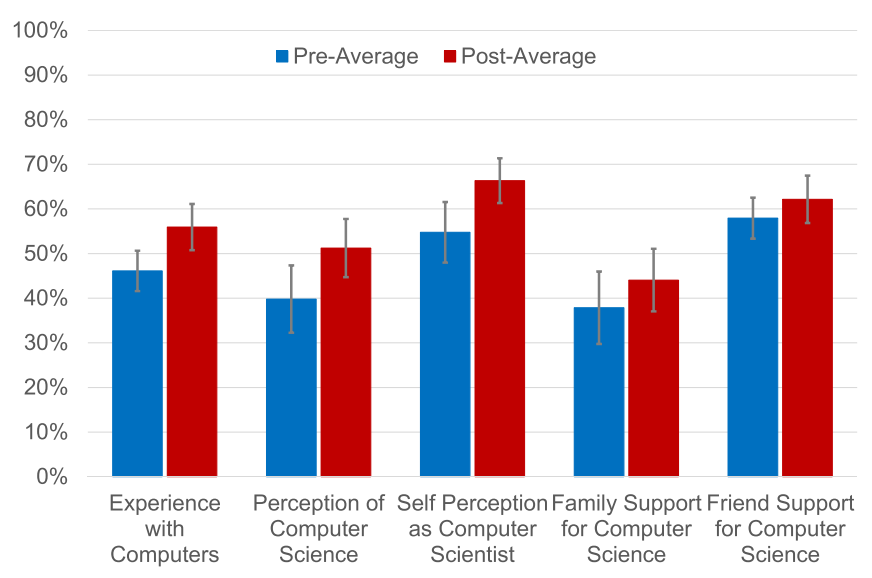

Fig. 1. Aggregate pre- and post-survey average responses.

positive growth in students' perceptions of their CS identities. The categorical aggregates showed significant differences from pre- to post-survey favoring students' experiences with CS (Mdiff = $0.33, t(107)=2.75, p<0.01)$, their perceptions of CS (Mdiff $=0.45, t(107)=2.50, p=0.01)$, their perceptions of themselves as computer scientists (Mdiff $=0.42, t(107)=2.39, p=0.01$ ), and family support for CS $(M \operatorname{diff}=0.61, t(107)=3.13, p<0.01)$. Students also reported more support for CS from their friends, but these results were not significant (Mdiff $=0.32, t(107)=$ 1.27, $p=0.10$ ) (see Tables 2 and 3).

Table 2 reports average post- minus pre-survey differences in response along with the effect size and $t$-test results for the individual items in the first three categorical aggregates relating to student experience with computers, perceptions of CS, and self-perceptions as computer scientists.

In terms of student experiences with computers, the item that showed the most substantial change related to the frequency with which students talked with friends and family about CS $($ Mdiff $=0.25, t(107)=3.91, p<0.01)$. Two other items that showed insignificant improvements were whether students take apart toys and computers to see how they work and whether they use tools to build things. The item asking students whether they write computer programs showed a negligible decline.

In characterizing students' perceptions of CS, there was a significant increase from pre- to posttest in the degree to which they believe computer scientists are respected (Mdiff $=0.18, t(107)=$ 2.63, $p<0.01$ ) and make a difference in the world (Mdiff $=0.23, t(107)=2.99, p<0.01)$. The survey also registered negligible changes in students' belief that they are good at CS and think CS is interesting.

Students' self-perceptions as computer scientists showed significant increases in the aggregate $(M \operatorname{diff}=0.42, t(107)=2.39, p=0.01)$ due to moderate increases in all items. Students demonstrated a statistically significant increase in their belief that they could do CS (Mdiff $=0.12$, $t(107)=1.84, p=0.03$ ), and statistically insignificant increases in their willingness to do things they can't master quickly (Mdiff $=0.09, t(107)=0.91, p=0.18$ ), willingness to try hard in the face of adverse signals (Mdiff $=0.12, t(107)=1.38, p=0.08)$, and enjoyment of understanding difficult things (Mdiff $=0.08, t(107)=1.03, p=0.15)$.

Table 3 reports average post- minus pre-survey differences in response along with the effect size and $t$-test results for the individual items in the last two categorical aggregates relating to family and friend support for CS. 
Table 2. Student Interest in Computer Science

\begin{tabular}{lrrrrr}
\hline \multicolumn{7}{c}{ Panel A: Experiences with Computers } \\
& Mean Dif.f Effect Size & Std. Error & $t$-Statistic & $p$-value \\
\hline$n=108$ & -0.01 & -0.01 & 0.06 & -0.16 & 0.56 \\
I write Computer Programs & 0.24 & 0.38 & 0.06 & $3.91^{* * *}$ & $<0.01$ \\
I talk with friends and family about CS & & & & & \\
I take apart toys, computers & 0.03 & 0.04 & 0.07 & 0.42 & 0.34 \\
$\quad$ to see how they work & 0.07 & 0.12 & 0.06 & 1.27 & 0.10 \\
$\begin{array}{l}\text { I use tools to build things } \\
\text { Sum Categorical Aggregate }\end{array}$ & 0.33 & 0.26 & 0.12 & $2.75^{* * *}$ & $<0.01$
\end{tabular}

\begin{tabular}{|c|c|c|c|c|c|}
\hline \multicolumn{6}{|c|}{ Panel B: Perceptions of Computer Science } \\
\hline$n=108$ & Mean Dif.f & ct Size & Error & $t$-statistic & -value \\
\hline I am good at CS & -0.02 & -0.02 & 0.07 & -0.26 & 0.60 \\
\hline I think CS is interesting & 0.06 & 0.09 & 0.07 & 0.90 & 0.19 \\
\hline Computer scientists are respected & 0.18 & 0.25 & 0.07 & $2.63^{* * *}$ & $<0.01$ \\
\hline Computer scientists make a & & & & & \\
\hline difference in the world & 0.23 & 0.29 & 0.08 & $2.99^{* * *}$ & $<0.01$ \\
\hline Sum Categorical Aggregate & 0.45 & 0.24 & 0.18 & $2.50^{* * *}$ & 0.01 \\
\hline
\end{tabular}

\begin{tabular}{lccrrr}
\hline \multicolumn{5}{c}{ Panel C: Self Perception as Computer Scientist } \\
\hline $\begin{array}{l}\text { Mean Dif.f Effect Size Std. Error } \\
\text { I can learn CS }\end{array}$ & 0.12 & 0.18 & 0.07 & $1.84^{* *}$ & 0.03 \\
$\begin{array}{l}\text { I don't like to do things } \\
\quad \text { I can't master quickly }\end{array}$ & 0.09 & 0.09 & 0.10 & 0.91 & 0.18 \\
$\begin{array}{l}\text { If people tell me I can't do } \\
\quad \text { something, I try harder }\end{array}$ & 0.12 & 0.13 & 0.09 & $1.38^{*}$ & 0.08 \\
$\begin{array}{l}\text { I enjoy trying to understand } \\
\text { difficult things }\end{array}$ & 0.08 & 0.10 & 0.08 & 1.03 & 0.15 \\
\hline Sum Categorical Aggregate & 0.42 & 0.23 & 0.17 & $2.39^{* * *}$ & 0.01 \\
\hline
\end{tabular}

Students' perceptions of family support for CS increases substantially (Mdiff $=0.61, t(107)=$ $3.13, p<0.01)$. Comparing post- with pre-survey responses demonstrates significant increases in the importance students' families assigned to getting good grades (Mdiff $=0.13, t(107)=$ $2.32, p=0.01)$ and trying their best (Mdiff $=0.12, t(107)=2.94, p<0.01)$, as well as their family's knowledge of their school performance (Mdiff $=0.22, t(107)=3.50, p<0.01)$. These responses also showed insignificant increases in the extent to which students' families thought CS was important for them to learn $(M \operatorname{diff}=0.10, t(107)=1.49, p=0.07)$ and interesting $($ Mdiff $=0.04, t(107)=0.51, p=0.30)$.

In evaluating students' friends support for CS, the categorical increase was not statistically significant $(M \operatorname{diff}=0.32, t(107)=1.27, p=0.10)$. Students did show statistically significant increases in the extent to which their friends thought CS is cool (Mdiff $=0.21, t(107)=2.01$, $p=0.02)$ and how much their friends like CS (Mdiff $=0.27, t(107)=2.41, p=0.01)$. However, there was a decline in the extent to which students' friends encourage them to do well in school $($ Mdiff $=-0.16, t(107)=-1.17, p=0.88)$.

\subsection{Results from Student CS Identity Interviews}

Students' experience with computers. Kang et al. [69] underscore the influence of students' personal and family backgrounds on disciplinary identification. Family factors, especially parental support, represents a key factor contributing to disciplinary identification $[6,7,93,97,115,116,130]$ The survey item with one of the largest increases was "I talk with friends and family about CS." These dis- 
Table 3. Community Support for Computer Science

\begin{tabular}{|c|c|c|c|c|c|}
\hline \multicolumn{6}{|c|}{ Panel A: Family Support for Computer Science } \\
\hline$n=108$ & Mean Dif.f & Effect Size & Std. Error & $t$-statistic & $p$-value \\
\hline $\begin{array}{l}\text { My family thinks CS is } \\
\text { important for me to learn }\end{array}$ & 0.10 & 0.14 & 0.07 & $1.49^{*}$ & 0.07 \\
\hline It's important to my family that & & & & & \\
\hline I get good grades & 0.13 & 0.22 & 0.06 & $2.32^{* * *}$ & 0.01 \\
\hline It's important to my family that & & & & & \\
\hline I try my best & 0.12 & 0.28 & 0.04 & $2.94^{* * *}$ & $<0.01$ \\
\hline $\begin{array}{l}\text { My family knows how well I'm } \\
\text { doing in school }\end{array}$ & 0.22 & 0.34 & 0.06 & $3.50^{* * *}$ & $<0.01$ \\
\hline $\begin{array}{l}\text { My family thinks CS } \\
\text { is interesting }\end{array}$ & 0.04 & 0.05 & 0.07 & 0.51 & 0.30 \\
\hline Sum Categorical Aggregate & 0.61 & 0.30 & 0.20 & $3.13^{* * *}$ & $<0.01$ \\
\hline Panel B: F & end Support & for Compute & Science & & \\
\hline$n=108$ & Mean Dif.f & Effect Size & Std. Error & $t$-statistic & $p$-value \\
\hline My friends think CS is cool & 0.21 & 0.19 & 0.11 & $2.01^{* *}$ & 0.02 \\
\hline $\begin{array}{l}\text { My friends encourage me } \\
\text { to do well in school }\end{array}$ & -0.16 & -0.11 & 0.13 & -1.17 & 0.88 \\
\hline My friends like computer science & 0.27 & 0.23 & 0.11 & $2.41^{* * *}$ & 0.01 \\
\hline Sum Categorical Aggregate & 0.32 & 0.12 & -0.26 & 1.27 & 0.10 \\
\hline
\end{tabular}

cussions provided multiple opportunities for children to perceive their families showing their support for CS and becoming more involved in their childrens' learning. Three major themes emerged from the analysis of parental involvement, which were rooted in their positive perceptions towards $\mathrm{CS}$, strong interests in CS, and viewing and creating work with their children.

An examination of how students believe their parents think about CS revealed the level of importance they assigned to learning of discipline. For example, one respondent said:

\footnotetext{
“My Mom's like, it's great because since you're already learning it, then you get the hang of it and when you're an adult you already have the hang of it. You are going to be like, "Oh, I already learned this in second grade, and then if I learned it in fifth grade, then I will learn [more] each year!"
}

This excerpt suggests that the student perceived their parents to be supportive of their CS learning and viewed it as valuable preparation for future learning. Students also reported showcasing their projects to their families, who expressed their appreciation of the CS curricula in its ability to realize their children's creativity and ideas.

\footnotetext{
"My mom was impressed...She was impressed because I went, 'Mom, look! I learned something new in class!' She's like, 'Oh that's really impressive; And then she's like, 'Oh It must be fun; And I'm like, 'Yeah, it's pretty fun.' She's like, Oh show me the um, the projects I had been doing. They're like, oh, really cool. What you did. Like they like everything I do and they're like, really? They, they call me like really creative."
}

As students like the respondent above experience CS across multiple contexts (at school, at home, with family), they begin to develop positive perceptions about how they themselves fit within CS 
communities [34, 91]. In addition to positive parental perceptions of CS, students discussed the benefits of talking about CS with their parents at home. For example, over half of those interviewed reported working together with their parents on Scratch projects.

"I talked to my mom and my dad. How fun it is sometimes if we can do projects together."

A small number of students said they had spent extended lengths of time working on complex projects with their parents.

"I kind of do a lot of outside programming with my, sometimes me and my dad do like games on scratch...We do like really fun games. Like we tried making our own Fortnite game but it came out really funny...It's really funny the look of...how I edited it because I edited it...It's kind of like a Pac Man. Characters are like Pac Man and then I got the idea from him because of his game...Yeah he helps me code a lot. He helps me with the levels...He's not a computer scientist, but he's fun."

A reasonable explanation for increased student perception of parental support could be the association they draw between classroom learning and the values and skills present in their families [123]. Students may practice CS with family members who also have interest in games, providing entry into CS not only for students, but also for families who might not otherwise have experience with the discipline.

Some students also reported practicing CS with their siblings and extended family and friends.

"I do it at my house. I did it. I, um, my grampa's friend's house, I did it basically everywhere I can take my Chromebook. I don't really get to use electronics so I just like being able to use Scratch."

"Yeah like...we did one [Scratch project] that was called "how I live with my brother and, and, and how I live with my sister.' It was fun. We did it together He said it's fun living with my sister. I liked it a lot because he's like creative.'

"My cousins, they showed me Code.org and I showed them Scratch. I show my cousins and sometimes my mom lets my friends come into my house? Yeah. Like in my friend Tina. Sometimes she visits and we don't know what else to do so we do Scratch."

Again, these students practiced CS learning beyond the traditional classroom lesson or afterschool coding club. As students began to develop their CS identities, their experiences with immediate and extended family helped to solidify their disciplinary identification. Together, these results provide important insights into how students' parental and family involvement influenced their experiences with CS and how those experiences shaped their identification with the CS discipline.

Students' perceptions of CS. Early exposure to CS facilitates students' perceptions of what it means to be a computer scientist and to do CS [34, 91]. The reciprocal relation between students' perceived selves and imagined future selves in the field of CS [69] are often governed by students' perceptions of what it means to be a competent CS actor [21]. From the interviews, we saw that the majority of students had an accurate understanding of who computer scientists are and what they do. When the participants were asked what CS is, over half of them made connections between $\mathrm{CS}$ and programming or coding. Furthermore, they provided multiple examples of what computer scientists do, such as studying computers, creating games, making apps, developing websites, and building things. A small number of those interviewed indicated that their own experiences with 
coding acted as fulcrums for further exploration. For example, one student imagined computer scientists as "making programs for kids to learn," which enabled her to identify with the profession in an age appropriate manner.

"They start making programs for kids to learn. And then they make programs...so like kids can see like what they do and then they could have like a background of like what they do."

This student believes that the child-friendly presentation of CS content has provided her with foundational knowledge of the types of practices adult computer scientists participate in. The age-appropriate curricular content and Scratch programming language provided a bridge to identification with a profession traditionally viewed as for adults only.

Computer scientists make a difference in the world. Students' belief that computer scientists make a difference in the world demonstrates how sociocultural aspects of computing go beyond classroom dynamics to encompass broader social issues. Students presented a variety of reasons why they believe that computer scientists make a difference in the world, including providing career opportunities, normalizing the making of mistakes, ensuring ethics and safety in computing, innovation, and making production more efficient.

Many of the students provided economic reasons for learning computing.

"They can inspire people in that they teach about coding and about other jobs that require coding so they could learn more about it.";

"I think people that do coding, it could help people understand more about it and...really get them to like...learn more about it, for like one day they could do it too and like probably get a better job."

Still other students believed that the normalization of mistakes was a valuable approach to learning that not only garnered respect, but actually made a difference in the lives of others.

"If you do mistakes you can change them...So that really makes a difference, that you can change your mistakes."

"So like kids can just like have fun doing stuff. If they make a mistake they don't have to worry, they can just go back and redo it"

One respondent mentioned the need to make the internet a safer place. When asked if they think computer scientists make a difference in the world, they said:

"I'm hoping the internet and making the internet safer...maybe they'll stop like cyber bullying, how they could like, uh, I don't know, but maybe they could stop people from like being mean to other people on the Internet and report them to the, to the owners of like, like if anybody is being really mean to anybody on Facebook, they can report it to the owners and the Facebook app so that way...nobody will have like to feel bad."

Finally, one student was able to see how CS concepts are at work in our everyday lives.

"Um, like making things by computer science, like coding things so we don't have to repeat things..... Like if you're building a wheel for a car and there's four wheels. Like, um, if you had a blueprint instead of having to write it four times, if he just like coded it out instead of having to repeat it four times."

This student's understanding that CS concepts are present outside of programming environments allowed them to explain how concepts such as loops could help society by making production more efficient. 
Student interest in CS. While the survey showed no significant difference from the pre- to posttest item measuring interest in CS, in the interviews students shared a variety of explanations as to why they thought CS was interesting, including their ability to express themselves freely, and the opportunity to leverage their varied resources to learn CS.

Many of those interviewed reported strong interest due to the freedom of expression embedded into instructional activities. The relatively unrestricted levels of choice embedded in the Scratch interface seemed to create positive perceptions of computer science and foster student ownership of their projects. This was made possible by the opportunities to make innovative design choices, and to take an iterative approach without facing negative feedback or criticism.

"I like [computer science]! It's fun to do when you're like bored sometimes cause you can create and then do what you want...Um, you can like erase it and you can do like anything....you can control. Yeah. Yeah. You can make your own thing right. And then you can change the name on it...Like my stuff. The sprites that you want."

This theme came up in discussions of how students personalized their projects. For example, one interviewee described how she created her own game as part of a Code.org challenge (Flappy Bird) that was embedded in the curriculum.
"So, um, in the Flappy Bird, um, game that we did, we can choose different types of sprites to do it. We did different types of code. So, for example, I did If hit the ground and you would lose the game and then you restart and then, um, the wallpaper would change when you made a score."

By adding personal touches to her programs, and personalizing her work, this student was able to leverage her creativity and imagination to grasp complex computational concepts, such as conditional logic. The comment below illustrates why many students reported liking CS: they can personalize it and be creative in their work.

"I like doing computer science because you get to create something on your own and you can personalize it and try to, you can try to be creative with doing it like that."

These students' creativity, however, did not reflect exclusively internal mental processes. On the contrary, their creative activities were social in nature as many students reported multiple sources of inspiration for creating their own projects.

"I have access to a computer, so sometimes I go scratch and explore others. I

look at other projects and use them and see how they created it."

Taken together, these results suggest that students were motivated to take ownership of their projects, and were able to find inspiration from both their own ideas and from reusing and remixing the work of others.

A final recurrent theme relating to students' interests in CS was a sense among the interviewees that the curriculum built upon their prior knowledge and experiences. The most commonly reported explanations of why CS was fun related to leveraging their interests, such as their gaming experiences, imagination, proclivities for building and making, creativity, expression of ideas, and desire to mentor others. One participant said:

"It's fun coding things because you can imagine. Your imagination comes to you when you're coding everything and then you code everything that you always imagine." 
This view was echoed by another participant, who identified the different modes of expression afforded by Scratch (i.e., stories, conversations, and games) as representing a key motivator. As this interviewee put it:

\begin{abstract}
"I try to make stories, conversations, and try to make games that include what I like. I already made a game, it is like a unicorn going to different backgrounds, and it makes music....and I included that because I like unicorns. It's like a way to express like what I [want], like when not like telling it in words but showing it."
\end{abstract}

In this excerpt, the interviewee prefers to express herself by showing not telling; she leverages her own semiotic resources to facilitate self-expression. This content-first approach to learning encourages students to access the discipline before engaging in unnecessary linguistic tasks, which may avert resources away from learning. There is a growing body of asset-based research on multilingual students illustrating how they draw on a range of resources (i.e., linguistic, cultural, semiotic, embodied, etc.) during CS learning activities [126? ]. Instructional practices that leverage these resources draw on multilingual students' full repertoires for learning, sense making, and identity development [126], thereby increasing their opportunities for full participation in CS [? ]. Together, these results provide important insights into how leveraging multilingual students' resources shapes how they envision themselves in CS.

Students' perceptions of themselves as computer scientists. There was a sense of self-efficacy among interviewees with regard to their perceptions of themselves as computer scientists. Survey results indicated a significant increase in students' beliefs that they can learn CS. When asked whether they can learn CS, the majority of participants responded in the affirmative and expressed a variety of perspectives as to how this learning was beneficial for them.

For example, one interviewee said:

\begin{abstract}
"Cause if sometime in the future I want to be a computer scientist, I would already have an experience with the computer. So it would be kind of easier for me to like, you know, like to do stuff and it wouldn't be anything new. Yeah, cause one day, if I ever grow up, I want to be like one of those guys that makes games."
\end{abstract}

Again, we see how students leverage their own experiences (e.g., making games) to make connections with the CS profession. There were some suggestions that learning CS would enable them to teach their peers. Another interviewee, when asked whether they could learn CS, said:

"I would help people learn, like about coding out and tell them about the event blocks and about the characters and about how to change backgrounds and how to take care of the internet and put it [the Scratch project] on there."

In sharing his expertise to support his classmates, this student developed a connection between his perception of self and the discipline of CS. The social recognition that accompanies identities marked by developing expertise provides further learning opportunities that may not arise without this type of recognition [14].

How positive attitudes toward making mistakes fostered persistence. One of the biggest affordances of the curriculum was teaching students to persevere when they made mistakes. In the survey, all students showed an increased belief in their ability to persist in the face of difficulty, and the item "If people tell me I can't do something, I try even harder" showed significantly positive growth. Students reported a variety of reasons for persisting in debugging their code by participating in the following activities: asking for help, applying multiple strategies including trying new blocks, and applying complex problem-solving strategies. 
For some of these students, help seeking was the strategy used to resolve initial feelings of frustration. For example, one student stumbled across a bug in which she needed a negative 10 as opposed to a positive 10. She reached to her teacher for help and learned about negative values. She expressed shock that a program can experience so many problems because of one little line (the negative sign).

"I think....when it was supposed to be negative 10 but I put 10 and not the negative one. And then when [my teacher] looked at her cheat code, it was negative 10 and then I think just for that little line, I couldn't do it?! Yeah. It's funny how it's one thing, but it's making a big difference in your code."

Although Scratch is a block-based program, it can still provide syntactical challenges for students. When asked what types of strategies she used when encountering problems in general, this participant reported trying new blocks or generalizing the advice her teacher gave her by switching positive and negative values in her code. This suggests that students may tend to overgeneralize strategies learned, indicating a greater need for strategy training in debugging exercises. Nevertheless, a variety of themes emerged from the analysis of student strategy use when encountering mistakes. The strategies students typically employed involved differing degrees of complexity, from trying new blocks and asking for help to experimenting and iterating on projects and engaging in planning and abstraction [16]. The most commonly reported technique reported for debugging mistakes was trying new blocks.

"If it didn't work I would've tried it again, but like with a different block...different, let's take one of them out. Which one didn't seem to [work] and try different blocks."

Turning now to more complex problem-solving techniques, a small number of participants used more advanced computational thinking practices to debug programs. In one case, a student participant persevered after making mistakes by applying multiple metacognitive strategies. When she encountered a mistake, she viewed it as a way to practice abstracting and modularizing [16], that is, she would decide which parts of the project she wanted to keep and which to exclude, make a plan, and then tinker and iterate with it to makes changes depending on her design preferences.

"Sometimes I do [make] mistakes, but um, I always make sure that if I did
make a mistake, I come back to it and try to fix it and solve the problem. Um,
I try to see...what I want, exactly what I want, I try to make a plan of what I
want. Then I kind of played with it and see if I liked it and then I'll change
stuff...if I liked something else."

In the above example, she referred to practicing identifying the problem within her code and on the user end to identify the problem while contextualizing these decisions based on her preferences.

Overall, students had a positive view of mistakes, most often viewing them as chances to learn something new.

\footnotetext{
"Like some people say that mistakes are our friends, they help us and then we can figure it out. Like, and learn something...So mistakes are like good for us. They help us a lot... like if you make a mistake in math or science, [you] can learn from that and try over again and get a better answer."
}

There were a few participants who reported overcoming the phobia associated with programming and working with computers in general. When asked about how they felt making mistakes, one participant said: 
"I feel like it's all right because it's not like going to harm me. I feel like it's just that sometimes I need a little bit more practice."

Finally, some students even leveraged their mistakes as an opportunity to improve their programs.

"When I made a mistake, I tried to fix it...in a way that helps me...like get it better. Like so then, so then I won't have to like keep...the same idea.'

In summary, for the participants in this study, mistakes provided more opportunities than pitfalls. Students were able to overcome their initial frustration to apply multiple strategies to debugging their code. Furthermore, they changed their orientation toward mistakes from negative to more positive views, seeing them, for example, as opportunities to learn and improve their work.

Support from peers. When the participants were asked what their friends thought about CS, the majority commented that their friends think CS is fun and exciting. Survey results corroborated this finding, as the item "My friends like computer science" showed a statistically significant increase. Furthermore, students expressed a variety of perspectives regarding how their friends provided support when they shared their work. Many students discussed the feedback they received from friends when showcasing projects. For example, one respondent said:

"Since they say it's good, they gave me suggestions too. Um, so like I, before I had the [sprite] move in my About Me project, I told them about it and they said, why don't you make something move?"

In addition to providing feedback, interviewees also reported receiving compliments from their friends on their work.

\section{"The first day when I told them about the About Me project, they're like 'Oh, I'm pretty impressed about this!' "}

Comparing the two results, it is clear that peer support created a positive influence on student learning in relation to building a sense of efficacy and community around their work.

Out-of-school learning environments. The final part of the interview included questions about students' out-of-school coding experiences. In many cases, they discussed practicing CS outside the classroom, such as at after-school coding clubs. One student reported working on her own time, "one day yes, one day no, when I have time." Furthermore, she drew inspiration from remixing and reusing ideas from her classmates. "I always have an idea. I always look at my classmates and then I see what they're making...and they give me an idea and then I do it my own way."

In another example, a participant made a racing game in their teacher's class and discussed how proud they were of it.

Student: "t's fun coding things because you can imagine...your imagination comes to you when you're coding everything and then you code everything that you always imagine. Then you can feel very proud when you make a game."

Interviewer: "That's awesome. Which one has been your favorite project so far or the one that you feel most proud of?"

Student: "Um, it was a racing game that I made."

Interviewer: "Oh, nice."

Student: "Um, Mrs. Jeanie's Coding Club afterschool."

Interviewer: "What did you do? That one there?"

Student: "Yeah."

Interviewer: "Nice...What are the rules for your racing game? How did you make it go?" 
Student: "One person can use the arrow keys, the up, down, left, and right arrow keys and the other one has used w, a, s, and d... and You had like a track and then whoever makes it first wins."

Students are typically proud of their work when they are able to extend their learning beyond the curriculum, while the extra practice helps to hone their skills and build confidence. Another student alluded to practicing Scratch at home, providing multiple reasons for going beyond what was assigned to create additional projects.

"I would use it for like, when I'm bored, when it's in an assignment, when I want to, when it's fun."

Comparing these two results, it can be seen that students practice CS outside the classroom for multiple reasons, including using their imagination, alleviating boredom, practicing their hobbies, and having fun. Interestingly, some students extend their learning beyond the classroom by seeing CS concepts in everyday life.

"Um, like if you're like walking, you don't just take one step, you take multiple
steps so it's like a loop."

This is a rather remarkable outcome as the student is able to contemplate computational thinking in the absence of explicit programming or curricular activities.

Finally, some students advanced their understanding by searching on the internet for CS-related content, such as science and engineering videos.

"I go to coding videos and watch science and engineering...I watch flocabulary... videos on, do you know of Flocabulary? It basically has science...we do it in our class."

Overall, these results indicate that CS learning extends beyond traditional learning environments to encompass how multilingual students' learning and identity development is shaped by participation outside of school, at home, after school, and within their communities.

\section{DISCUSSION}

The findings from this study are corroborated by previous literature highlighting the role of family support [49], self-perception [39], and formal and informal learning experiences [96] in developing student identification in STEM. These results also build on previous research that demonstrates the importance of early intervention in developing students' later interest in CS careers [51, 121]. Finally, the findings point to the strong need to engage multilingual students in disciplinary practices that leverage their existing resources, which reduces the burden of having to learn language and CS at the same time [73, 77, 78]. By integrating practices shown to be effective [18], we provided a context in which existing resources could be used to make CS learning more immediately relevant and valuable to students. This has resulted in students pursuing CS learning across a variety of formal and informal educational settings.

\subsection{Students' Experiences with Computers}

Findings from this study suggest that multilingual students' discussions of CS with family and friends helped to normalize it and contributed to greater identification with the field [65]. While family and community engagement are critical to providing responsive CS education [6, 7, 93, $97,115,116,130]$, the current focus on testing, which constrains other disciplines such as math and science, leaves little time for CS learning and fails to account for the sociocultural processes that underlie multilingual student identity development. Sharing projects with family and friends 
has had the reciprocal advantage of shaping how students perceive being seen by members of their households and communities, namely, as having CS expertise. Furthermore, the time students spent sharing projects and talking about CS outside of school provided more opportunities for them to perceive themselves as capable and invested participants in CS communities. As CS begins to be systematically implemented in elementary grades, it is incumbent upon educational policy makers, curriculum developers, and practitioners to highlight the role of family and peer support in developing students' interests.

Furthermore, the findings revealed that students began to associate classroom learning with the values and skills present in their families. These findings are consistent with recent research in computing, maker spaces, and other scientific disciplines [60, 100, 123]. When students find their work to be personally meaningful, they begin to make connections between their own knowledge and experience and the curriculum. In a similar study, indigenous boys made connections between computational principles and working with their parents on car mechanics [111]. Findings such as these highlight that, to encourage students' engagement with CS, it is crucial to provide several points of connection that draw from students' rich cultural and familial traditions and wealth of knowledge. These findings are corroborated by prior research into the role of familismo [105], meaning strong connections to immediate and extended family that value collaboration and community, in positively influencing the development of STEM identities for predominantly Latinx students [105].

\subsection{Students' Perceptions of Computer Scientists}

Multilingual student identification with the discipline is contingent upon their perceptions of who competent actors are and how they value these actors' roles [34]. Students had an accurate understanding of who computer scientists are and what they do, and they described numerous ways in which computer scientists make a difference in the world. In perceiving how computer scientists contribute to solving broader social and economic problems, they developed a better understanding of how computing can be used to solve problems in the broader community. As a next step, curriculum developers could leverage these perceptions to encourage students to use computational thinking to solve problems within their own communities. Through efforts such as these, students have the potential to transform computational thinking into computational action that has a direct impact in their own communities [122]. Furthermore, as part of the pre- and postsurvey, we asked students the following open-ended questions: "Who are computer scientists and what do they do?" We plan on analyzing these data for future research to understand how students' understanding of computer scientists grew both as a class and at the individual-student level.

\subsection{Students' Interest in CS}

While the survey results indicated that students did not significantly increase their interest in CS, the interviews painted a different picture. Findings from the interview are consistent with previous findings that self-expression $[16,62,100]$ and the ability to leverage their varied resources $[73,77,78]$ are key contributors to developing student interest in computing. The personal choice integrated into Scratch-based activities and projects played an integral role in disrupting stereotypes about who does CS [68]. As students personalized their work, they began to take ownership and envision themselves as producers of computational artifacts. Furthermore, students' ability to showcase their knowledge instead of "telling" it was reflected in the curriculum's content-first approach, which provides equitable points of access for multilingual students to engage in complex content [74]. An underlying contribution of this content-first approach to learning is that students are encouraged to access the discipline before engaging in linguistic tasks, which may unnecessarily avert resources away from learning [74]. It is through content learning that stu- 
dents interact and communicate with one another, beginning to co-construct knowledge, and thus become active creators of disciplinary practices. To this end, the principles underlying the practices embedded in our curriculum include examining what STEM subject matter "does," not as a codified body of knowledge, but as a vehicle for making sense of complex problems and phenomena [132].

Furthermore, previous research on multilingual student engagement in STEM has underscored the importance of engaging these students in meaningful interaction that provides authentic contexts for language use [18]. In our study, student identity construction was social in nature: as their project design and development did not occur in isolation, but instead was the dynamic result of concerted efforts from teacher and peers. This finding is corroborated by theoretical works and empirical studies that take a sociocultural approach to identity development [21, 65, 90]; as students view their learning as collaborative and relational, their disciplinary interest strengthens.

\subsection{Students' Perceptions of Themselves as Computer Scientists}

Students developed a greater sense of efficacy in their ability to learn CS, rooted in making connections to the profession and positioning themselves as experts within the field. Such findings are consistent with previous research that highlights how positioning students as experts not only increases their efficacy beliefs [21] but also provides further opportunities for learning. Dorner et al. [36] examine how predominantly Latinx, multilingual students often act as language brokers at multiple socialization sites, such as the home, in which immigrant parents may not speak English, and the classroom, which presents a site for dominant use of the target language. These brokering opportunities provide students opportunities to position themselves as experts within these sites and foster stronger disciplinary identities [42, 103]. As this study represents the exploratory phase of a larger effort to refine, test, and scale the computational thinking curriculum, we have added additional content to the curriculum to encourage students to see experts from similar cultural and social backgrounds as themselves, enabling students to see themselves within the field of CS. One revision to the curriculum has been to add "Memorable Mentor" videos, in which students learn about programming from predominantly Latinx computer scientists, and then reflect on how these experts' work is relevant to solving problems globally or within their local communities.

\subsection{Students' Perceptions of Making Mistakes}

Unlike math and science, CS frequently proposes multiple solutions to a single problem, which results in reframing "mistakes" as potential learning opportunities. This has implications for equity, as multilingual students may use their everyday sense-making abilities, instead of disciplinespecific language, to articulate their problem-solving approaches in the target language, resulting in their teachers viewing their approaches to problem solving as mistakes rather than as novel, complex, and innovative solutions [131]. Furthermore, as debugging is a recognized computational thinking practice [16], fixing mistakes in code is a principle component of CS learning. What is less well studied is how developing a positive attitude toward making mistakes fosters persistence. Recent research has shown how having elementary students embody debugging activities through unplugged activities such as walking through mazes fostered persistence in coding [3,4]. Given the extent to which these students viewed making mistakes as opportunities to learn, further research on the relationship between debugging and persistence in CS is warranted.

\subsection{Support from Peers}

While in aggregate, the category for peer support did not show significant growth, the item "My friends like computer science" showed a statistically significant increase. As mentioned above, disciplinary identification occurs when activities are viewed as socially typical [65]. Conversely, 
students tend to disidentify with a discipline when they see its activities as socially atypical. This disidentification can also spread through peer groups by way of peer pressure [118]. Due to its virulence, disidentification represents a key contributor to underrepresentation of marginalized students, such as women, Black students, and students of color [70]. It then becomes key to distinguish incidences when students "choose not to learn" from those in which they have difficulty grappling with the material, when examining the effects of disidentification on student learning [71]. Dornyei and Ottó [37] find that positive peer dynamics represent an essential component for increasing multilingual students' motivation in linguistically diverse classrooms.

\subsection{Learning CS Outside of School}

Instructional interventions such as our culturally and linguistically responsive computational thinking curriculum provide equitable CS education for multilingual students by affording a sociocultural approach that extends beyond traditional learning environments to encompass how multilingual students' learning and identity development is shaped by participation across social and cultural contexts $[34,91]$. Results from the interviews highlighted how multilingual students' learning and identity development was shaped by participation outside of school, at home, after school, and within their communities. These findings are corroborated by CS and STEM education research on informal learning environments, which presents promising opportunities for creative expression and reshaping how diverse youth view literacy, learning, and expression [100]. Research on multilingual students indicates that situating science learning within informal contexts has been an effective approach for teacher education [26, 57, 120]. Given these promising results, future research on multilingual student learning of CS in informal settings would help to uncover the factors that contribute to meaningful participation.

\subsection{Limitations}

A clear limitation of this study is the lack of a control group in measuring students' learning and identification with CS. This has been a key issue in elementary studies of CS learning, as CS has not yet become a credentialed subject, and opportunities for comparing an intervention to business as usual are limited. Nevertheless, the next phase of our project will compare students receiving the computational thinking curriculum to students receiving "business as usual" elementary subjects, to see that the computational thinking curriculum increased their CS achievement while having no impact on their proficiency levels in math and ELA.

Another limitation is that we adapted a validated survey commonly used in science classrooms (ISM); it is possible that results are skewed in the positive direction as students already have knowledge of science before they begin a specific intervention, but may not have as much knowledge of CS. Our project team has acknowledged this limitation, and as this study represents the first phase of a larger intervention to refine, test, and scale the curriculum, we have chosen another student attitude survey to measure CS identities.

Furthermore, it is possible that students exhibited ceiling effects with respect to their interest in CS. However, the survey included several other questions, across multiple categories, that highlight how their identities grew along several dimensions. A potential strength of the follow-up interviews is that they enabled us to discover why the students were interested in CS, despite any ceiling effects that might obscure the extent of their growth.

Another limitation of this article is that we did not have student- and teacher-level data due to the nascent nature of our Research Practice Partnership; therefore, we could not explore how students' backgrounds compared to those of the teachers. In the course design process of CS curricula, such as the MOOC Integrating Computational Thinking into the High School Curriculum in Puerto Rico, researchers have recruited teachers with heritage similar to students [95], which has been shown to provide greater academic and social outcomes for Latinx students [129]. Future 
research should focus on how teacher demographics influence student identification with the field of CS.

In addition, there are several limitations to using linguistic scaffolding when it is not implemented properly. The instructional moments in which sentence frames provide affordances include when they are used to reinforce concepts that are learned inductively. To this end, concepts should first be taught inductively in a manner that engages students in peer-to-peer interaction. During this phase of instruction, language scaffolding has been shown to stifle communication, insofar as it limits students' rhetorical choices to prescriptive language. While providing language support is integral to teaching language and CS together, there is much to learn about plurilingual approaches such as translanguaging and content-first approaches to STEM instruction that decolonize traditional views of academic language teaching by emphasizing student understanding over language usage $[52,88,126]$.

Finally, as we are focusing on multilingual students, it could be argued that we should focus on their linguistic identities rather than their CS identities. We argue that the content-first approach to the curriculum and the multimodal affordances of Scratch provided entry points into the discipline that these students might not otherwise encounter in a language-heavy math and/or science curriculum. These points of access, along with the connections students made between the curriculum and the values of their families, and considering the multiple settings in which students practiced CS (at home, with friends, at after school coding clubs, with extended family), all contributed to overall greater identification with the field.

\subsection{Conclusions}

Too often, educators assume that multilingual students come to school lacking the conceptual or linguistic resources necessary for learning CS. In contrast to these assumptions, the instructional models we embedded in the curriculum leveraged multilingual students' existing resources (conceptual, social, linguistic, cultural, semiotic, etc.) to open new possibilities for CS education. The purposefully tailored curriculum, coupled with students' home and school access to Chromebooks, provided opportunities for students to learn and identify with the materials through participation with family and peers in and outside of school. We recommend that teachers pay close attention to the dominant narratives surrounding who does CS and combat stereotypes by encouraging students to view themselves as capable participants in CS communities. This can be achieved by leveraging students' personal and family backgrounds, garnering parental support, making connections between the CS profession and broader social issues, positioning students as experts, engaging peer support networks, and providing multiple points of connection between formal and informal learning environments.

In this study, we demonstrated the ways in which students developed disciplinary identification with the field of CS through their engagement in a culturally and linguistically responsive curriculum. Throughout their engagement, students were able to leverage their multiple resources across formal, home, and informal learning contexts. The most encouraging part of this story is that students had multiple ways to identify with the instructional materials in a manner that leveraged their identities to support CS learning. This offers promising possibilities for educators who wish to provide early exposure to CS in a manner that shapes student interests and inspires them to pursue the profession.

\section{ACKNOWLEDGMENTS}

We would first like to thank the teachers and students who invited us into their classrooms and supported this work. We would also like to thank the reviewers for giving this work a platform. 


\section{REFERENCES}

[1] Jonathan Adams. 2013. The fourth age of research. Nature 497, 7451 (2013), 557-560.

[2] Veronica Arizaga Aguayo. 2020. Life After the EL Label: Conversations aboutIdentity, Language, and Race. PhD Dissertation, San Francisco University.

[3] Junghyun Ahn. 2020. Computational Thinking in Children: The Impact of Embodiment on Debugging Practices in Programming. Ph.D. Dissertation. Teachers College, Columbia University.

[4] Jung-Hyun Ahn, Yaoli Mao, Woonhee Sung, and John B. Black. 2017. Supporting debugging skills: Using embodied instructions in children's programming education. In Society for Information Technology \& Teacher Education International Conference. Association for the Advancement of Computing in Education (AACE), 19-26.

[5] Ayana Allen-Handy, Valerie Ifill, Raja Y. Schaar, Michelle Rogers, and Monique Woodard. 2020. Black girls STEAMing through dance: Inspiring STEAM literacies, STEAM identities, and positive self-concept. In Challenges and Opportunities for Transforming From STEM to STEAM Education. IGI Global, 198-219.

[6] Louise Archer, Jennifer DeWitt, Jonathan Osborne, Justin Dillon, Beatrice Willis, and Billy Wong. 2012. Science aspirations, capital, and family habitus: How families shape children's engagement and identification with science. American Educational Research fournal 49, 5 (2012), 881-908.

[7] Pamela R. Aschbacher, Marsha Ing, and Sherry M. Tsai. 2014. Is science me? Exploring middle school students' STE-M career aspirations. Journal of Science Education and Technology 23, 6 (2014), 735-743.

[8] James Banks, Kathryn Au, Arnetha F. Ball, Philip Bell, Edmund Gordon, Kris Gutiérrez, S. Brice-Heath, Carol D. Lee, J. Mahiri, N. Nasir, et al. 2007. Learning in and out of school in diverse environments: Life-long, life-wide, life-deep. Retrieved March 22, 2022 from https://education.uw.edu/cme/LIFE.

[9] Patrick Barmby, Per M. Kind, and Karen Jones. 2008. Examining changing attitudes in secondary school science. International fournal of Science Education 30, 8 (2008), 1075-1093.

[10] Brigid Barron, Caitlin Kennedy Martin, Lori Takeuchi, and Rachel Fithian. 2009. Parents as learning partners in the development of technological fluency.

[11] Angela Calabrese Barton and Kimberley Yang. 2000. The culture of power and science education: Learning from Miguel. Journal of Research in Science Teaching: The Official fournal of the National Association for Research in Science Teaching 37, 8 (2000), 871-889.

[12] Sreyashi Jhumki Basu and Angela Calabrese Barton. 2007. Developing a sustained interest in science among urban minority youth. Journal of Research in Science Teaching: The Official Journal of the National Association for Research in Science Teaching 44, 3 (2007), 466-489.

[13] Philip Bell, Carrie Tzou, Leah Bricker, and AnnMarie D. Baines. 2012. Learning in diversities of structures of social practice: Accounting for how, why and where people learn science. Human Development 55, 5-6 (2012), 269-284.

[14] Kera Bell-Watkins, Tiffany Barnes, and Nathan Thomas. 2009. Developing computing identity as a model for prioritizing dynamic K-12 computing curricular standards. Fournal of Computing Sciences in Colleges 24, 3 (2009), 125-131.

[15] Marco A. Bravo and Gina N. Cervetti. 2014. Attending to the language and literacy needs of English learners in science. Equity \& Excellence in Education 47, 2 (2014), 230-245.

[16] Karen Brennan and Mitchel Resnick. 2012. New frameworks for studying and assessing the development of computational thinking. In Proceedings of the 2012 Annual Meeting of the American Educational Research Association, Vol. 1. 25.

[17] Nancy W. Brickhouse and Jennifer T. Potter. 2001. Young women's scientific identity formation in an urban context. fournal of Research in Science Teaching: The Official Journal of the National Association for Research in Science Teaching 38, 8 (2001), 965-980.

[18] Recognizing Assets that English Learners Bring. 2018. English Learners in STEM Subjects: Transforming Classrooms, Schools, and Lives. National Academies of Sciences.

[19] Bryan A. Brown and Kihyun Ryoo. 2008. Teaching science as a language: A "content-first" approach to science teaching. Journal of Research in Science Teaching 45, 5 (2008), 529-553.

[20] Angela Calabrese Barton and Christina Berchini. 2013. Becoming an insider: Teaching science in urban settings. Theory Into Practice 52, 1 (2013), 21-27.

[21] Angela Calabrese Barton, Hosun Kang, Edna Tan, Tara B. O’Neill, Juanita Bautista-Guerra, and Caitlin Brecklin. 2013. Crafting a future in science: Tracing middle school girls' identity work over time and space. American Educational Research fournal 50, 1 (2013), 37-75.

[22] Heidi B. Carlone, Julie Haun-Frank, and Angela Webb. 2011. Assessing equity beyond knowledge-and skills-based outcomes: A comparative ethnography of two fourth-grade reform-based science classrooms. Fournal of Research in Science Teaching 48, 5 (2011), 459-485.

[23] Heidi B. Carlone, Lacey D. Huffling, Terry Tomasek, Tess A. Hegedus, Catherine E. Matthews, Melony H. Allen, and Mary C. Ash. 2015. 'Unthinkable' Selves: Identity boundary work in a summer field ecology enrichment program for diverse youth. International fournal of Science Education 37, 10 (2015), 1524-1546. 
[24] Heidi B. Carlone, Catherine M. Scott, and Cassi Lowder. 2014. Becoming (less) scientific: A longitudinal study of students' identity work from elementary to middle school science. Fournal of Research in Science Teaching 51, 7 (2014), 836-869.

[25] Vivian Chávez and Elisabeth Soep. 2005. Youth radio and the pedagogy of collegiality. Harvard Educational Review 75, 4 (2005), 409-434.

[26] Kathryn Ciechanowski, SueAnn Bottoms, Ana Lucia Fonseca, and Tyler St. Clair. 2015. Should Rey Mysterio drink gatorade? Cultural competence in afterschool STEM programming. Afterschool Matters 21 (2015), 29-37.

[27] Code.org, CSTA and ECEP Alliance. 2020. 2020 State of Computer Science Education: Illuminating Disparities. Retrieved from https://advocacy.code.org/stateofcs.

[28] Darnell Cole and Araceli Espinoza. 2008. Examining the academic success of Latino students in science technology engineering and mathematics (STEM) majors. fournal of College Student Development 49, 4 (2008), 285-300.

[29] Vivian Cook. 2012. Multicompetence. The Encyclopedia of Applied Linguistics.

[30] James E. Cote and Charles G. Levine. 2002. Identity formation. Agency and Cultural.

[31] National Research Council et al. 2012. A Framework for K-12 Science Education: Practices, Crosscutting Concepts, and Core Ideas. National Academies Press.

[32] Alison Crump. 2014. Introducing LangCrit: Critical language and race theory. Critical Inquiry in Language Studies 11, 3 (2014), 207-224.

[33] Spanish Family Code Nights: Advancing CSforAll. [n.d.]. https://stemforall2019.videohall.com/presentations/1600.

[34] Ron Darvin and Bonny Norton. 2015. Identity and a model of investment in applied linguistics. Annual Review of Applied Linguistics 35 (2015), 36-56.

[35] Jill Denner and M. A. Robb. 2020. Engaging families in STEM education for young children. Presented at the Hawaiian International Conference on Education, Honolulu, HI.

[36] Lisa M. Dorner, Marjorie Faulstich Orellana, and Christine P. Li-Grining. 2007. "I helped my mom," and it helped me: Translating the skills of language brokers into improved standardized test scores. American fournal of Education 113, 3 (2007), 451-478.

[37] Zoltan Dornyei and István Ottó. 1998. Motivation in action: A process model of L2 motivation.

[38] Richard A. Duschl, Heidi A. Schweingruber, and Andrew W. Shouse. 2007. Taking science to school: Learning and teaching science in grades K-8. Eurasia fournal of Mathematics, Science \& Technology Education 3, 2 (2007), 163-166.

[39] Jacqueline S. Eccles and Allan Wigfield. 2000. Schooling's influences on motivation and achievement. Securing the Future: Investing in Children from Birth to College, 153-181.

[40] Jana Echevarria, Catherine Richards-Tutor, Rebecca Canges, and David Francis. 2011. Using the SIOP model to promote the acquisition of language and science concepts with English learners. Bilingual Research fournal 34, 3 (2011), 334-351.

[41] Ron Eglash. 2004. Appropriating Technology: Vernacular Science and Social Power. University of Minnesota Press.

[42] Noah Weeth Feinstein, Sue Allen, and Edgar Jenkins. 2013. Outside the pipeline: Reimagining science education for nonscientists. Science 340, 6130 (2013), 314-317.

[43] Google (Firm) and Gallup (Firm). 2015. Images of computer science: Perceptions among students, parents and educators in the US.

[44] Nelson Flores and Jonathan Rosa. 2015. Undoing appropriateness: Raciolinguistic ideologies and language diversity in education. Harvard Educational Review 85, 2 (2015), 149-171.

[45] Anne M. Gadermann, Martin Guhn, and Bruno D. Zumbo. 2012. Estimating ordinal reliability for Likert-type and ordinal item response data: A conceptual, empirical, and practical guide. Practical Assessment, Research, and Evaluation 17, 1 (2012), 3.

[46] Ofelia García. 2009. Bilingualism and translanguaging. Bilingual Education in the 21st Century: A Global Perspective (2009), 42-72.

[47] Ofelia García and Li Wei. 2014. Language, bilingualism and education. In Translanguaging: Language, Bilingualism and Education. Springer, 46-62.

[48] Pauline Gibbons. 2007. Mediating academic language learning through classroom discourse. In International Handbook of English Language Teaching. Springer, 701-718.

[49] Shannon K. Gilmartin, Erika Li, and Pamela Aschbacher. 2006. The relationship between interest in physical science/engineering, science class experiences, and family contexts: Variations by gender and race/ethnicity among secondary students. Journal of Women and Minorities in Science and Engineering 12, 2-3 (2006).

[50] Joanna Goode, Jane Margolis, and Gail Chapman. 2014. Curriculum is not enough: The educational theory and research foundation of the exploring computer science professional development model. In Proceedings of the 45th ACM Technical Symposium on Computer Science Education. 493-498.

[51] Sandy Graham and Celine Latulipe. 2003. CS girls rock: Sparking interest in computer science and debunking the stereotypes. In Proceedings of the 34th SIGCSE Technical Symposium on Computer Science Education. 322-326. 
[52] Scott E. Grapin, Lorena Llosa, Alison Haas, and Okhee Lee. 2021. Rethinking instructional strategies with English learners in the content areas. TESOL fournal 12, 2 (2021), e557.

[53] Kris D. Gutiérrez and A. Susan Jurow. 2016. Social design experiments: Toward equity by design. Journal of the Learning Sciences 25, 4 (2016), 565-598.

[54] Kris D. Gutiérrez and Barbara Rogoff. 2003. Cultural ways of learning: Individual traits or repertoires of practice. Educational Researcher 32, 5 (2003), 19-25.

[55] Alison Haas, Scott E. Grapin, Daniel Wendel, Lorena Llosa, and Okhee Lee. 2020. How fifth-grade English learners engage in systems thinking using computational models. Systems 8, 4 (2020), 47.

[56] Michael Alexander Kirkwood Halliday. 1973. Explorations in the functions of language. Macmillan of Canada.

[57] Danielle B. Harlow. 2012. The excitement and wonder of teaching science: What pre-service teachers learn from facilitating family science night centers. Journal of Science Teacher Education 23, 2 (2012), 199-220.

[58] Peter Häussler and Lore Hoffmann. 2002. An intervention study to enhance girls' interest, self-concept, and achievement in physics classes. Journal of Research in Science Teaching 39, 9 (2002), 870-888.

[59] Suzanne Hidi. 1990. Interest and its contribution as a mental resource for learning. Review of Educational Research 60, 4 (1990), 549-571.

[60] J. Howell, C. Tofel-Grehl, D. A. Fields, and G. J. Ducamp. 2016. E-textiles to teach electricity: An experiential, aesthetic, handcrafted approach to science. Teacher Pioneers: Visions from the Edge of the Map. ETC. Press, Pittsburgh, 232-245.

[61] Nataliya V. Ivankova, John W. Creswell, and Sheldon L. Stick. 2006. Using mixed-methods sequential explanatory design: From theory to practice. Field Methods 18, 1 (2006), 3-20.

[62] Sharin Jacob, Leiny Garcia, and Mark Warschauer. 2020. Leveraging multilingual identities in computer science education. In Technology and the Psychology of Second Language Learners and Users. Palgrave Macmillan, Cham, 309-331.

[63] Sharin Jacob, Ha Nguyen, Leiny Garcia, Debra Richardson, and Mark Warschauer. 2020. Teaching computational thinking to multilingual students through inquiry-based learning. In 2020 Research on Equity and Sustained Participation in Engineering, Computing, and Technology (RESPECT'20), Vol. 1. IEEE, 1-8.

[64] Sharin Jacob, Ha Nguyen, Colby Tofel-Grehl, Debra Richardson, and Mark Warschauer. 2018. Teaching computational thinking to English learners. NYS TESOL fournal 5, 2 (2018).

[65] Betsy James DiSalvo, Sarita Yardi, Mark Guzdial, Tom McKlin, Charles Meadows, Kenneth Perry, and Amy Bruckman 2011. African American men constructing computing identity. In Proceedings of the SIGCHI Conference on Human Factors in Computing Systems. 2967-2970.

[66] Joy Janzen. 2008. Teaching English language learners in the content areas. Review of Educational Research 78, 4 (2008), 1010-1038.

[67] Yasmin Kafai, Kristin Searle, Crîstobal Martinez, and Bryan Brayboy. 2014. Ethnocomputing with electronic textiles: Culturally responsive open design to broaden participation in computing in American Indian youth and communities. In Proceedings of the 45th ACM Technical Symposium on Computer Science Education. 241-246.

[68] Yasmin B. Kafai and Quinn Burke. 2014. Connected Code: Why Children Need to Learn Programming. MIT Press.

[69] Hosun Kang, Angela Calabrese Barton, Edna Tan, Sandra D. Simpkins, Hyang-yon Rhee, and Chandler Turner. 2019. How do middle school girls of color develop STEM identities? Middle school girls' participation in science activities and identification with STEM careers. Science Education 103, 2 (2019), 418-439.

[70] Sandra Katz, John Aronis, David Allbritton, Christine Wilson, and Mary Lou Soffa. 2003. Gender and race in predicting achievement in computer science. IEEE Technology and Society Magazine 22, 3 (2003), 20-27.

[71] H. Kohl. 1995. I Won't Learn From You. New Press.

[72] Okhee Lee, Lorena Llosa, Scott Grapin, Alison Haas, and Marcelle Goggins. 2019. Science and language integration with English learners: A conceptual framework guiding instructional materials development. Science Education 103, 2 (2019), 317-337.

[73] Okhee Lee, Lorena Llosa, Feng Jiang, Alison Haas, Corey O’Connor, and Christopher D. Van Booven. 2016. Elementary teachers' science knowledge and instructional practices: Impact of an intervention focused on English language learners. Journal of Research in Science Teaching 53, 4 (2016), 579-597.

[74] Okhee Lee and Amy Stephens. 2020. English learners in STEM subjects: Contemporary views on STEM subjects and language with English learners. Educational Researcher 49, 6 (2020), 426-432.

[75] Caroline Linse. 2013. English language learner a term that warrants scrutiny. Journal of Educational Thought/Revue de la Pensée Educative (2013), 107-122.

[76] S. Loucks-Horsley, N. Love, K. E. Stiles, S. Mundry, and P. W. Hewson. 2010. Designing Professional Development for Teachers of Science and Mathematics. Vol. 2, Corwin Press.

[77] E. Lyon, S. Tolbert, J. Ll Solis, Tl Stoddart, I I Salinas, Cl Knox, Bl Roth, and Ml Butler. 2016. Teaching English learners through science-language integration: Linking a conceptual framework to secondary teacher preparation. In Strand 7 Symposium at the Annual Conference of the National Association of Research in Science Teaching. 
[78] Edward G. Lyon, Sara Tolbert, Jorge Solís, Patricia Stoddart, and George C. Bunch. 2016. Secondary Science Teaching for English Learners: Developing Supportive and Responsive Learning Contexts for Sense-Making and Language Development. Rowman \& Littlefield.

[79] Jane Margolis, Jean J. Ryoo, Cueponcaxochitl D. M. Sandoval, Clifford Lee, Joanna Goode, and Gail Chapman. 2012. Beyond access: Broadening participation in high school computer science. ACM Inroads 3, 4 (2012), 72-78.

[80] Alexis Martin, Frieda McAlear, and Allison Scott. 2015. Path not found: Disparities in access to computer science courses in California high schools. Online submission.

[81] Joel McFarland, Bill Hussar, Jijun Zhang, Xiaolei Wang, Ke Wang, Sarah Hein, Melissa Diliberti, Emily Forrest Cataldi, Farrah Bullock Mann, and Amy Barmer. 2019. The condition of education 2019. NCES 2019-144. National Center for Education Statistics.

[82] Judith L. Meece, Phillip Herman, and Barbara L. McCombs. 2003. Relations of learner-centered teaching practices to adolescents' achievement goals. International fournal of Educational Research 39, 4-5 (2003), 457-475.

[83] Kate Menken. 2013. Emergent bilingual students in secondary school: Along the academic language and literacy continuum. Language Teaching 46, 4 (2013), 438.

[84] Sarah Michaels and Catherine O'Connor. 2015. Conceptualizing talk moves as tools: Professional development approaches for academically productive discussion. Socializing Intelligence Through Talk and Dialogue, 347-362.

[85] Punya Mishra, Aman Yadav, Deep-Play Research Group, et al. 2013. Rethinking technology \& creativity in the 21st century. TechTrends 57, 3 (2013), 10-14.

[86] Elizabeth Birr Moje, Kathryn McIntosh Ciechanowski, Katherine Kramer, Lindsay Ellis, Rosario Carrillo, and Tehani Collazo. 2004. Working toward third space in content area literacy: An examination of everyday funds of knowledge and discourse. Reading Research Quarterly 39, 1 (2004), 38-70.

[87] Luis C. Moll, Cathy Amanti, Deborah Neff, and Norma Gonzalez. 1992. Funds of knowledge for teaching: Using a qualitative approach to connect homes and classrooms. Theory Into Practice 31, 2 (1992), 132-141.

[88] Suhanthie Motha. 2020. Is an antiracist and decolonizing applied linguistics possible? Connecting the past to the future. In 2020 Conference of the American Association for Applied Linguistics (AAAL'20). AAAL.

[89] Na'ilah Suad Nasir and Jamal Cooks. 2009. Becoming a hurdler: How learning settings afford identities. Anthropology \& Education Quarterly 40, 1 (2009), 41-61.

[90] Na'ilah Suad Nasir and Victoria Hand. 2008. From the court to the classroom: Opportunities for engagement, learning, and identity in basketball and classroom mathematics. The fournal of the Learning Sciences 17, 2 (2008), 143-179.

[91] Bonny Norton. 2001. Non-participation, imagined communities and the language classroom. Learner Contributions to Language Learning: New Directions in Research 6, 2 (2001), 159-171.

[92] Brian A. Nosek, Mahzarin R. Banaji, and Anthony G. Greenwald. 2002. Math = male, me = female, therefore math $\neq$ me. Journal of Personality and Social Psychology 83, 1 (2002), 44.

[93] Gwen Nugent, Bradley Barker, Greg Welch, Neal Grandgenett, ChaoRong Wu, and Carl Nelson. 2015. A model of factors contributing to STEM learning and career orientation. International fournal of Science Education 37, 7 (2015), $1067-1088$

[94] Bureau of Labor Statistics. 2018. Occupational Outlook Handbook: Computer and Information Technology. https: //www.bls.gov/ooh/computer-and-information-technology/home.htm.

[95] Patricia Ordóñez Franco, Joseph Carroll-Miranda, María López Delgado, Eliud Gerena López, and Grace Rodríguez Gómez. 2018. Incorporating computational thinking in the classrooms of Puerto Rico: How a MOOC served as an outreach and recruitment tool for computer science education. In Proceedings of the 49th ACM Technical Symposium on Computer Science Education. 296-301.

[96] Jonathan Osborne, Sue Collins, Mary Ratcliffe, Robin Millar, and Rick Duschl. 2003. What "ideas-about-science" should be taught in school science? A Delphi study of the expert community. Fournal of Research in Science Teaching 40, 7 (2003), 692-720.

[97] Daphna Oyserman, Daniel Brickman, and Marjorie Rhodes. 2007. School success, possible selves, and parent school involvement. Family Relations 56, 5 (2007), 479-489.

[98] William R. Penuel and Barry J. Fishman. 2012. Large-scale science education intervention research we can use. Fournal of Research in Science Teaching 49, 3 (2012), 281-304.

[99] William R. Penuel, T. Lee, and Bronwyn Bevan. 2014. Designing and building infrastructures to support equitable STEM learning across settings. Research + Practice Collaboratory Research Synthesis. San Francisco: The Exploratorium.

[100] Kylie A. Peppler and Yasmin B. Kafai. 2007. From SuperGoo to Scratch: Exploring creative digital media production in informal learning. Learning, Media and Technology 32, 2 (2007), 149-166.

[101] Nichole Pinkard, Sheena Erete, Caitlin K. Martin, and Maxine McKinney de Royston. 2017. Digital youth divas: Exploring narrative-driven curriculum to spark middle school girls' interest in computational activities. Fournal of the Learning Sciences 26, 3 (2017), 477-516. 
[102] Núria Planas and Mamokgethi Setati. 2009. Bilingual students using their languages in the learning of mathematics. Mathematics Education Research fournal 21, 3 (2009), 36-59.

[103] Joseph L. Polman, Alan Newman, Ellen Wendy Saul, and Cathy Farrar. 2014. Adapting practices of science journalism to foster science literacy. Science Education 98, 5 (2014), 766-791.

[104] Mitchel Resnick, John Maloney, Andrés Monroy-Hernández, Natalie Rusk, Evelyn Eastmond, Karen Brennan, Amon Millner, Eric Rosenbaum, Jay Silver, Brian Silverman, and Yasmin B. Kafai. 2009. Scratch: programming for all. Communications of theACM 52, 11 (2009), 60-67.

[105] Sarah Rodriguez, Amy Pilcher, and Norma Garcia-Tellez. 2021. The influence of familismo on Latina student STEM identity development. fournal of Latinos and Education 20, 2 (2021), 177-189.

[106] Barbara Rogoff. 1997. Evaluating development in the process of participation: Theory, methods, and practice building on each other. Change and Development: Issues of Theory, Method, and Application (1997), 265-285.

[107] Ann S. Rosebery. 2008. Teaching Science to English Language Learners: Building on Students' Strengths. NSTA Press.

[108] Ann S. Rosebery, Beth Warren, and Faith R. Conant. 1992. Appropriating scientific discourse: Findings from language minority classrooms. The fournal of the Learning Sciences 2, 1 (1992), 61-94.

[109] Johnny Saldaña. 2021. The Coding Manual for Qualitative Researchers. SAGE.

[110] Kim Schildkamp and Wilmad Kuiper. 2010. Data-informed curriculum reform: Which data, what purposes, and promoting and hindering factors. Teaching and Teacher Education 26, 3 (2010), 482-496.

[111] Kristin A. Searle and Yasmin B. Kafai. 2015. Boys' needlework: Understanding gendered and indigenous perspectives on computing and crafting with electronic textiles. In ICER. 31-39.

[112] Sabrina F. Sembiante and Zhongfeng Tian. 2021. Culturally sustaining approaches to academic languaging through systemic functional linguistics. Language and Education 35, 2 (2020), 101-105.

[113] Mia Shaw and Yasmin Kafai. 2020. Charting the identity turn in K-12 computer science education: Developing more inclusive learning pathways for identities. In The 14th International Conference of the Learning Sciences (ICLS'20).

[114] Lauren M. Shea and Therese B. Shanahan. [n.d.]. We are all talking to learn science: Finding the right fit.

[115] Sandra D. Simpkins, Jennifer A. Fredricks, and Jacquelynne S. Eccles. 2015. Families, schools, and developing achievement-related motivations and engagement.

[116] Sandra D. Simpkins, Chara D. Price, and Krystal Garcia. 2015. Parental support and high school students' motivation in biology, chemistry, and physics: Understanding differences among Latino and Caucasian boys and girls. Journal of Research in Science Teaching 52, 10 (2015), 1386-1407.

[117] Megan Smith. 2016. Computer science for all. 2016. The White House President Barack Obama: USA.

[118] Claude M. Steele. 1992. Race and the schooling of black Americans. The Atlantic Monthly 269, 4 (1992), 68-78.

[119] Claude M. Steele. 1997. A threat in the air: How stereotypes shape intellectual identity and performance. American Psychologist 52, 6 (1997), 613.

[120] Joan Sullivan and Mary Hatton. 2011. Math and science night. Science and Children 48, 5 (2011), 58-63.

[121] Robert H. Tai, Christine Qi Liu, Adam V. Maltese, and Xitao Fan. 2006. Planning early for careers in science. Life Science 1, 0.2 (2006).

[122] Mike Tissenbaum, Josh Sheldon, and Hal Abelson. 2019. From computational thinking to computational action. Communications of the ACM 62, 3 (2019), 34-36.

[123] Colby Tofel-Grehl, Deborah Fields, Kristin Searle, Cathy Maahs-Fladung, David Feldon, Grace Gu, and Chongning Sun. 2017. Electrifying engagement in middle school science class: Improving student interest through e-textiles. fournal of Science Education and Technology 26, 4 (2017), 406-417.

[124] Riva Tukachinsky, Dana Mastro, and Moran Yarchi. 2017. The effect of prime time television ethnic/racial stereotypes on Latino and Black Americans: A longitudinal national level study. fournal of Broadcasting \& Electronic Media 61, 3 (2017), 538-556.

[125] Katie Van Horne and Philip Bell. 2017. Youth disciplinary identification during participation in contemporary projectbased science investigations in school. fournal of the Learning Sciences 26, 3 (2017), 437-476.

[126] Sara Vogel, Christopher Hoadley, Ana Rebeca Castillo, and Laura Ascenzi-Moreno. 2020. Languages, literacies and literate programming: Can we use the latest theories on how bilingual people learn to help us teach computational literacies? Computer Science Education 30, 4 (2020), 420-443.

[127] Sara Vogel, Rafi Santo, and Dixie Ching. 2017. Visions of computer science education: Unpacking arguments for and projected impacts of CS4All initiatives. In Proceedings of the 2017 ACM SIGCSE Technical Symposium on Computer Science Education. 609-614.

[128] Jeannette M. Wing. 2006. Computational thinking. Communications of the ACM 49, 3 (2006), 33-35.

[129] Adam Wright, Michael A. Gottfried, and Vi-Nhuan Le. 2017. A kindergarten teacher like me: The role of student-teacher race in social-emotional development. American Educational Research fournal 54, 1_suppl (2017), 78S-101S. 
[130] Nicole Zarrett and J. S. Eccles. 2009. The role of the family and community in extracurricular activity. AERA Monograph Series: Promising Practices for Family and Community Involvement During High School 4 (2009), 27-51.

[131] Ninger Zhou, Yucheng Cao, Sharin Jacob, and Debra Richardson. 2020. Teacher perceptions of equity in high school computer science classrooms. ACM Transactions on Computing Education (TOCE) 20, 3 (2020), 1-27.

[132] Susan Gomez Zwiep and William J. Straits. 2013. Inquiry science: The gateway to English language proficiency. fournal of Science Teacher Education 24, 8 (2013), 1315-1331.

[133] R. P. Moses and C. Cobb. 2001. Organizing algebra: The need to voice a demand. Social Policy 31, 4 (2001), 4-12.

Received January 2021; revised November 2021; accepted November 2021 